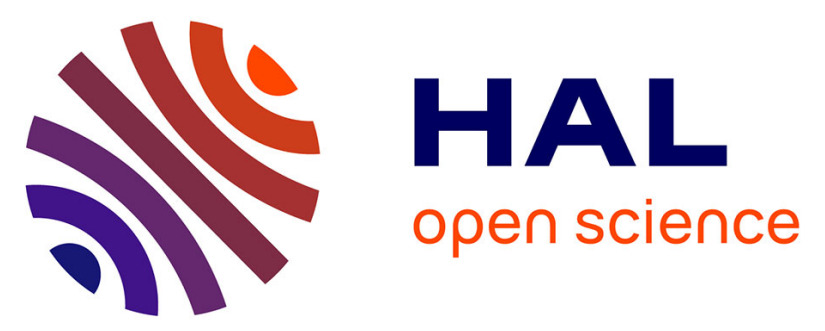

\title{
The morphology and evolution of chondrichthyan cranial muscles: a digital dissection of the elephantfish Callorhinchus milii and the catshark Scyliorhinus canicula
}

Richard P Dearden, Rohan Mansuit, Antoine Cuckovic, Anthony Herrel, Dominique Didier, Paul Tafforeau, Alan Pradel

\section{To cite this version:}

Richard P Dearden, Rohan Mansuit, Antoine Cuckovic, Anthony Herrel, Dominique Didier, et al.. The morphology and evolution of chondrichthyan cranial muscles: a digital dissection of the elephantfish Callorhinchus milii and the catshark Scyliorhinus canicula. Journal of Anatomy, In press, 10.1111/joa.13362 . hal-03103769

\section{HAL Id: hal-03103769 \\ https://hal.science/hal-03103769}

Submitted on 8 Jan 2021

HAL is a multi-disciplinary open access archive for the deposit and dissemination of scientific research documents, whether they are published or not. The documents may come from teaching and research institutions in France or abroad, or from public or private research centers.
L'archive ouverte pluridisciplinaire HAL, est destinée au dépôt et à la diffusion de documents scientifiques de niveau recherche, publiés ou non, émanant des établissements d'enseignement et de recherche français ou étrangers, des laboratoires publics ou privés. 


\section{The morphology and evolution of chondrichthyan cranial muscles: a}

\section{2 digital dissection of the elephantfish Callorhinchus milii and the}

\section{3 catshark Scyliorhinus canicula.}

4 Running title: Cranial muscles of Callorhinchus and Scyliorhinus

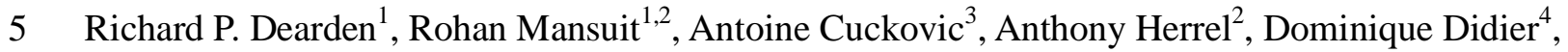

6 Paul Tafforeau ${ }^{5}$, Alan Pradel $^{1}$

7

$8{ }^{1}$ CR2P, Centre de Recherche en Paléontologie-Paris, Muséum national d'Histoire naturelle,

9 Sorbonne Université, Centre National de la Recherche Scientifique, CP 38, 57 rue Cuvier, F75231

10 Paris cedex 05, France.

$11{ }^{2}$ UMR 7179 (MNHN-CNRS) MECADEV, Département Adaptations du Vivant, Muséum National

12 d'Histoire Naturelle, Paris, France

$13{ }^{3}$ Université Paris Saclay, 91190 Saint-Aubin, France

$14{ }^{4}$ Department of Biology, Millersville University, Millersville, PA 17551, USA

$15 \quad{ }^{5}$ European Synchrotron Radiation Facility, Grenoble, France 


\section{Abstract}

18 The anatomy of sharks, rays, and chimaeras (chondrichthyans) is crucial to understanding the evolution of the cranial system in vertebrates, due to their position as the sister group to bony fishes (osteichthyans). Strikingly different arrangements of the head in the two constituent chondrichthyan groups - holocephalans and elasmobranchs - have played a pivotal role in the formation of evolutionary hypotheses targeting major cranial structures such as the jaws and pharynx. However, despite the advent of digital dissections as a means of easily visualizing and sharing the results of anatomical studies in three dimensions, information on the musculoskeletal systems of the chondrichthyan head remains largely limited to traditional accounts, many of which are at least a century old. Here we use synchrotron tomography acquire 3D data which we used to carry out a digital dissection of a holocephalan and an elasmobranch widely used as model species: the elephantfish, Callorhinchus milii, and the small-spotted catshark, Scyliorhinus canicula. We describe and figure the skeletal anatomy of the head, labial, mandibular, hyoid, and branchial cartilages in both taxa as well as the muscles of the head and pharynx. We make new observations, particularly regarding the branchial musculature of Callorhinchus, revealing several previously unreported or previously ambiguous structures. Finally, we review what is known about the evolution of chondrichthyan cranial muscles from their fossil record and discuss the implications for muscle homology and evolution, broadly concluding that the holocephalan pharynx is likely derived from a more elasmobranch-like form. This dataset has great potential as a resource, particularly for researchers using these model species for zoological research, functional morphologists requiring models of musculature and skeletons, as well as for palaeontologists seeking comparative models for extinct taxa.

Keywords (English): digital dissection, cranial muscles, holocephalan, elasmobranch, 
bioRxiv preprint doi: https://doi.org/10.1101/2020.07.30.227132; this version posted July 31, 2020. The copyright holder for this preprint (which was not certified by peer review) is the author/funder, who has granted bioRxiv a license to display the preprint in perpetuity. It is made available under aCC-BY-NC-ND 4.0 International license.

41 


\section{Introduction}

43 Cartilaginous fishes (Chondrichthyes) comprise only a small fraction of total jawed vertebrate diversity (Nelson et al., 2016) but are key to understanding the evolution of jawed vertebrates. As the sister-group to the more diverse and disparate bony fishes (ray-finned fishes, lobe-finned fishes, and tetrapods) their anatomy and physiology provides a valuable outgroup comparison which, probably incorrectly, has often been held to represent "primitive states" for jawed vertebrates as a

whole. The greatly divergent cranial morphologies displayed by the two constituent sister groups of Chondrichthyes - elasmobranchs and holocephalans - have themselves led to much debate, both over chondrichthyan origins and those of jawed vertebrates more broadly. For these reasons, anatomists, embryologists, and physiologists have intensively studied chondrichthyan anatomy over the last two centuries. Recently, tomographic methods have allowed the advent of "digital dissections", where an organism's anatomy can be non-destructively visualized and communicated in the form of interactive datasets. These studies have run the gamut of mammals (Cox and Faulkes, 2014; Sharp and Trusler, 2015), archosaurs (Klinkhamer et al., 2017; Lautenschlager et al., 2014), lissamphibians (Porro and Richards, 2017), and actinopterygians (Brocklehurst et al., 2019). Although aspects of cartilaginous fish anatomy have been examined (Camp et al., 2017; Denton et al., 2018; Tomita et al., 2018), three-dimensional information on the cranial musculoskeletal system is limited.

We aim to address this with a digital dissection of the hard tissues and musculature of two representatives of the Chondrichthyes: Callorhinchus milii Bory de Saint-Vincent 1823, a holocephalan, and Scyliorhinus canicula Linnaeus 1758, an elasmobranch. Callorhinchus milii is a callorhinchid, the sister-group to all other holocephalans (Inoue et al., 2010; Licht et al., 2012) and 
historically one of the best known holocephalans due to its being one of only two species to inhabit shallow, nearshore waters (Didier, 1995). As a result, the musculature of the genus has been described several times (Edgeworth, 1935; Kesteven, 1933; Luther, 1909a; Shann, 1919), most recently with Didier (1995) providing a detailed overview of the anatomy and systematics of holocephalans, including Callorhinchus. Scyliorhinus canicula is a scyliorhinid, a carcharhiniform galeomorph elasmobranch. Because of the accessibility of adults, eggs, and embryos to European researchers (it is abundant in nearshore habitats in the northeastern Atlantic) the species has featured heavily in embryological and physiological studies of chondrichthyans (Coolen et al., 2008; de Beer, 1931; Hughes and Ballintijn, 1965; Oulion et al., 2011; Reif, 1980). While accounts exist of its gross anatomy (Allis, 1917; Edgeworth, 1935; Luther, 1909b; Nakaya, 1975; Ridewood, 1899; Soares and Carvalho, 2013), detailed and fully illustrated accounts are surprisingly rare in comparison to the similarly common Squalus.

Here we use a synchrotron tomographic dataset to provide accounts of anatomy of the cartilages and musculature of the head in Callorhinchus milii and Scyliorhinus canicula. We examine dissection-based reports of muscle anatomy in the light of our reconstructed models. By combining this information with what is known about fossil taxa, we assess scenarios of morphological evolution of chondrichthyan cranial muscles. More broadly, we aim to provide the research community with valuable three-dimensional data on the anatomy of these taxa. 
83 Both specimens described here are the same as those used in Pradel et al. (2013) and full specimen 84 acquisition and scanning details can be found therein. In brief, both specimens were scanned on 85 beamline ID19 of the European Synchrotron Radiation Facility (ESRF). The specimen of Callorhinchus milii is a female at embryonic stage 36 (Didier et al., 1998) $\square$, the stage immediately

87 prior to hatching, and was originally collected from the Marlborough Sounds, New Zealand. It was 88 scanned in a $75 \%$ ethanol solution at a voxel size of 30 microns, and a single distance phase 89 retrieval process was used to gain differential contrast of the specimen's tissues. The Scyliorhinus 90 canicula specimen is a juvenile, reared at the Laboratoire Evolution, Génome et Spéciation, UPR 9034 CNRS, Gif-Sur-Yvette, France, which had reached the stage of independent feeding when

92 humanely killed. It was scanned in a $100 \%$ ethanol solution using a holotomographic approach at a 93 voxel size of 7.45 microns.

94 Volumes for both specimens were reconstructed using the ESRF software PyHST. $\square$ Segmentations of the 3D data were carried out using Mimics versions 15-21 (Materialise). Images of the resulting three-dimensional models were created using Blender v2.80 (blender.org). Unfortunately, the

97 resolution of the scans was not sufficient to observe innervation in most cases, so this is done 98 throughout the text with reference to the literature. 
99

\section{Results}

100 The cranial skeletons of Callorhinchus milii and Scyliorhinus canicula have been described before

101 in detail, but below we provide a brief description of the neurocranial and pharyngeal skeleton to

102 supplement our account of the muscles. We also describe the muscles' attachments and innervation.

103 Where necessary we note disagreements about precise accounts of the innervation of the cranial

104 muscles. The supporting information includes 3D files of all structures described (Dearden et al.

1052020, SI1-3).

106 Callorhinchus milii

107 Cranial Cartilages

108 The head skeleton of Callorhinchus comprises the neurocranium (Fig. 1), to which the

109 palatoquadrates are fused, the mandible, formed from the two medially fused Meckel's cartilages, a

110 series of six paired labial cartilages surrounding the mouth, a non-suspensory hyoid arch, and five

111 branchial arches (Fig. 2). Like all other living holocephalans the head skeleton is antero-posteriorly

112 compact: the lower jaw extends posteriorly only as far as the back of the orbits, and all other

113 pharyngeal cartilages are located ventral to the neurocranium. The whole arrangement is posteriorly

114 bounded by ventrally joined scapulocoracoids.

115 The neurocranium of Callorhinchus milii is tall, with an extensive rostrum, enlarged orbits, and a

116 laterally broad otic region (Fig. 1). The olfactory capsules (Fig. 1c; olf. cap.) take the form of two

117 rounded, ventrally open bulbs, closely set at the extreme anterior end of the neurocranium. A short

118 dorsal process (Fig. 1a, c; dors. proc.) projects from the apex of each capsule. Between the olfactory 
119 capsules three long rostral rods project anteriorly to support the animal's "trunk": one median rod 120 along the midline (Fig. 1a, b; m. rost. rod) and a pair of lateral rods (Fig. 1a, b; 1. rost. rod). Below 121 them a beak projects ventrally, forming the anterior end of the mouth's roof, and carrying the 122 vomerine toothplates (Fig. 2g; vom. tp.). At the very base of the beak's lateral sides are a pair of 123 small fossae with which the pedicular cartilages articulate (Fig. 1a, ped. foss.). The ethmoid region 124 is long, with steeply sloping sides separated at the midline by the ethmoid crest which has a marked 125 ethmoid process at its middle (Fig. 1a, b, c, eth. proc.). A pair of foraminae in the orbits form the 126 entrance to the ethmoid canal for the superficial ophthalmic complex (Fig. 1a; eth. can. oph.), which 127 runs anteriorly through the midline length of the ethmoid region. About two fifths of the way along the canal's length it is punctured by a lateral foramen for the entry of the profundus $\left(\mathrm{V}_{1}\right)$ nerve (Fig. 1a; eth. can. prof.), anterior to this several small foraminae along its length allow twigs of the superficial ophthalmic complex + profundus to exit onto the ethmoid surface (Fig. 1a; eth. can. tw.).

131 The canal opens anteriorly through a pair of teardrop-shaped foraminae posterior to the nasal 132 capsules (Fig. 1a, c; eth. can. ant.). On the ventral slope of the ethmoid region, a row of three 133 foraminae provide passage for branches of the nasal vein behind the nasal capsules (Fig. 1a; for. br. nas.). At the postero-ventral corner of the ethmoid region are a pair of stout quadrate processes (Fig. 1a, b, e; quad. proc.), which flare laterally to meet the Meckelian cartilages (Fig. 2b; Meck.).

The orbits in Callorhinchus are very large, occupying the neurocranium's full height and about two

137 fifths of its length. Anteriorly they are bounded by laterally projecting antorbital processes (Fig. 1a,

138 b; antorb. proc.) and a preorbital fascia (Didier, 1995). The inner orbital wall is formed by an 139 extensive sphenoptic membrane (Figs. 2, 3). Posterior to the antorbital processes the roof of the 140 neurocranium pinches in laterally, meaning that there only a narrow supraorbital shelf (Fig. 1a, b;

141 supraorb. shelf) to the orbits, before expanding posteriorly into the postorbital ridge (Fig. 1a;

142 postorb. ridge), which curves ventrally to form the rear wall of the orbit. Ventrally the orbits are 143 bounded by a broad, flat suborbital shelf (Fig. 1a; suborb. shelf), which at its lateral extent broadens 
144 into a marked ridge. Just above the level of the suborbital shelf is a large foramen in the sphenoptic

145 membrane for the optic (II) nerve (Fig. 3a, b; opt. (II) op.), and immediately posteriorly to this is a

146 small opening for the central retinal (optic) artery (Fig. 3a, b; ret. art.). Antero-ventrally is a small

147 orbitonasal canal foramen for the nasal vein (Fig. 3a; orbnas. can.). The superficial ophthalmic

148 complex $(\mathrm{V}+$ anterodorsal lateral line) enters the orbit through a dorso-posterior foramen (Fig. 3a,

149 b; sup. oph. for.), and then exits, entering the ethmoid canal, via a large ophthalmic foramen in the

150 antero-dorsal part of the orbit (Fig. 3a; oph. for.). In the posteroventral corner of the orbit is a large

151 foramen through which the trigeminal (V) and facial (VII) nerves enter the orbit (Fig. 3a, b; for. V+

152 VII). Two foraminae in the ventral part of the orbit provide exits for the hyomandibular (Figs. 1e,

153 3b; hyo. fac. (VII)) and palatine (Figs. 1e, 3b; pal. fac. (VII)) branches of the facial nerve onto the

154 neurocranial floor. The orbital artery also enters the orbit through the palatine foramen.

155 Between the orbits the neurocranial roof forms a shallowly convex surface, which becomes more

156 pronounced posteriorly. This shallow roof curves slightly ventrally, and at its apex is a small,

157 unchondrified area (Fig. 1c; unchond. area). The roof pinches in laterally to meet the endolymphatic

158 duct opening (Fig. 1c; endo. duct), which is large and subcircular. Posteriorly to this is an occipital

159 crest (Fig. 1d; occ. crest), which is pronounced dorsally, before becoming lower and being

160 interrupted by the foramen magnum. The otic capsules form two pronounced bulges on either side

161 of the neurocranium, with the anterior, posterior, and lateral canals forming a rough triangle of

162 ridges, dorso-anteriorly, posteriorly, and laterally. Ventral to the lateral ridge the sides of the

163 neurocranium pinch in before expanding again to form the edge of the neurocranial floor. The

164 foramen magnum (Fig. 1d; for. mag.) is a large circular opening about half the height of the

165 neurocranium, ventral to which is the shallow, rectangular occipital cotylus (Fig. 1d; occ. cot.),

166 bounded by two long, thin condyles sit on either side. A small foramen in the centre of the occipital

167 cotylus permits entry for the notochord (Fig. 1d; noto. for.), which extends anteriorly into the

168 dorsum sellae. 
169

The ventral surface of the neurocranium is markedly broad and flat, tapering and becoming slightly convex anteriorly where it forms the roof of the mouth. The palatine toothplates (Fig. 2g; pal. tp.) sit between the vomerine toothplates and the quadrate processes. At the approximate centre of the neurocranial floor lies a deep hypophyseal groove (Fig. 1e; hyp. groove.). Postero-laterally to the hypophyseal groove are the two paired foraminae through which the hyomandibular (Figs. 1e ,3b; hyo. fac. (VII)) and palatine (Figs. 1e ,3b; pal. fac. (VII)) branches of the facial nerve (VII) exit the orbit. Antero-laterally to the hypophyseal groove are a pair of foraminae through which the efferent pseudobranchial arteries enter the braincase (Fig. 1e; eff. pseud.). Anteriorly to these are paired orbitonasal canals through which the nasal veins pass into the orbit (Fig. 1e; orbnas. can.), which mark the posterior end of paired grooves carrying the nasal veins over the neurocranial floor from the nasal capsule to the orbits (Fig. 1e; nas. vein gr.). Posteriorly, either side of the neurocranial floor tapers medially and joins the otic region, while the central floor continues posteriorly to form the base of the occiput. Just dorsally to this is a row of foraminae for the glossopharyngeal (IX) nerve (Fig. 1e; gloss for. (IX)), vagus (X) nerve (Fig. 1e; vagus for. (X)), and anterior spinal nerves (Fig. 1e; spin. nerves).

Meckel's cartilages (Fig. 2b; Meck.) are fused at a medial symphysis to form a single, bow-shaped element. This element has a flat surface, the ventral face of which is shallowly convex. Shallow fossae in the dorsal surface carry the mandibular toothplates (Fig. 2e, f; mand. tp.). The ventroposterior midline deepens into a pronounced chin process (Fig. 2e, chin pr.) onto which the $m$. mandibulohyoidei attach. At the anterior midline is an unchondrified embayment (Fig. 2b, unchond. emb.). The articular regions of the mandibular cartilages are positioned at their extreme posterior ends, and as in other chondrichthyans, are double-articulating. A lateral process (Fig. 2g; lat. proc.) and a medial fossa (Fig. 2g; med. foss.) on the quadrate process articulate with a medial process (Fig. 2e; med. proc.) and lateral fossa (Fig. 2e; lat. foss.) on Meckel's cartilage. Anteriorly to the 
193 mandibulae posterior attaches (Fig. 2f; add. ang.).

195 Six pairs of labial cartilages are present in Callorhinchus: the premandibular, inferior maxillary,

196 superior maxillary, pedicular, premaxillary, and prelabial. These surround the mouth, supporting the

197 animal's fleshy lip, and provide the insertion surfaces for a series of muscles and tendons. The

198 premandibular cartilages (Fig. 2b; premand.) are broad and plate-like, sitting laterally to the

199 mandibles. Above them are the short, hockey-stick shaped inferior maxillary (Fig. 2b; imax.)

200 cartilages. The dorsal tip of these articulate with the superior maxillary cartilages (Fig. 2b; smax.) -

201 large, curved elements with a dorsal process. The anterior tip of this meets the back of the round

202 head of the pedicular cartilage (Fig. 2b; ped., which posteriorly curves medially to meet a small

203 fossa in the ethmoid region. Ventrally the head of the pedicular cartilage meets the premaxillary

204 cartilage, a short, flat element which extends into the tissue of the upper lip (Fig. 2b; pmax.).

205 Dorsally the head of the pedicular cartilage meets the prelabial cartilage (Fig. 2b; plab.), a gentle

206 sigmoid that extends dorsally, and which is secured to the rostral rods by labial and rostral

207 ligaments.

The hyoid arch does not articulate with the neurocranium, and comprises a basihyal and paired ceratohyals, hyomandibulae (epihyals), and pharyngohyals. The basihyal (Fig. 2c, basih.) is a very the ceratohyals. The ceratohyal (Fig. 2c, ceratoh.) is a large, curved, and flattened element, with a 
217 dorsal and ventral zones. Posteriorly to the hyoid arch no branchial or extrabranchial rays are 218 present.

219 The branchial skeleton comprises five branchial arches, lying entirely ventrally to the 220 neurocranium. The midline floor of the pharynx is formed by a series of basibranchials (Fig. 2c, 221 bbr.), a very small anterior one, two middle ones that between them form a box-shape, and a long, 222 posterior basibranchial copula (Fig. 2c, cop.). Articulating with these are four paired hypobranchials 223 (Fig. 2c; hbr). These are directed antero-medially, each contacting at least two pharyngeal arches. 224 The first hypobranchial contacts the ceratohyal and first ceratobranchial as well as the anterior 225 basibranchial, the second hypobranchial contacts the first and second ceratobranchials, the third 226 hypobranchial contacts the second and third ceratobranchials and extends between the second and 227 third basibranchials, while the fourth hypobranchial is larger than the others and contacts the third, 228 fourth, and fifth ceratobranchials in addition to the third basibranchial and the basibranchial copula. 229 The ceratobranchials are gently curved, with short processes to contact the hypobranchials, and the 230 fifth ceratobranchial is slightly flattened and closely associated with the fourth. The first three 231 branchial arches have three separate epibranchials which are flattened and square, with a ventral 232 process that articulates with the ceratobranchials (Fig. 2c; cbr). They also have a pronounced 233 anterior process that in the first arch, underlies the hyomandibula, and in the posterior arches 234 contacts the anterior pharyngobranchial. Two separate pharyngobranchials (Fig. 2d; pbr.) articulate 235 on the posterior corners of the first two epibranchials, projecting posteriorly, also contacting the 236 anterior processes of the second and third epibranchials. They are well-developed and flat, with a 237 dorsal groove over which the second and third efferent branchial arteries pass. At the posterior end 238 of the dorsal branchial skeleton is a complex cartilage (Fig. 2d; post. comp.), taking the place of the 239 fourth and fifth epibranchials, as well as the third, fourth, and fifth pharyngobranchials. This 240 structure is roughly triangular in shape, and shallowly convex medially, with pronounced postero241 ventral and postero-dorsal processes. On its antero-ventral side it contacts the fourth and fifth 
242 ceratobranchials, before projecting anteriorly into a process that contacts the postero-dorsal corner

243 of the third epibranchial. The dorsal surface of this process is obliquely grooved for the fourth

244 efferent branchial artery, and there is a large foramen in this anterior process through which the fifth

245 branchial artery passes.

\section{Cranial Musculature}

247 This account follows the terminology of Didier (1995) and Anderson (2008), which itself follows

248 Vetter (1878), Edgeworth (1935), and Shann (1919).

M. adductor mandibulae posterior (Fig. 4a; m. add. mand. post.)

250 Description: A small muscle with an origin along the anterior edge of the suborbital shelf, antero-

251 ventrally to the orbit. Didier (1995) also reports an origin on the preorbital fascia, which is not

252 visible in our scans - if this is present it is small. The muscle lies in a shallow depression anterior to

253 the quadrate process, anteriorly overlapping the $m$. adductor mandibulae anterior, with a surface

254 divided into two parts by the passage of the mandibular branch of the trigeminal nerve $\left(\mathrm{V}_{3}\right)$. It

255 inserts over a small angle on Meckel's cartilage (Fig. 2f; add. ang.), joining with a sheet of

256 connective tissue slung ventrally around Meckel's cartilage.

257 Innervation: Trigeminal (V) nerve (Didier, 1995).

258 Remarks: The m. adductor mandibulae posterior's extent is variable in different holocephalan

259 genera, and is relatively reduced in Rhinochimaera and Chimaera (Didier, 1995).

260 M. adductor mandibulae anterior (Fig. 4a; m. add. mand. ant.) 
261 Description: Larger than the m. adductor mandibulae posterior and lies entirely preorbitally. Its

262 very broad origin extends from the preorbital fascia, across the medial section of the antorbital

263 process, and along the ethmoid crest. It narrows ventrally to insert over the posterior part of

264 Meckel's cartilage, joining the connective tissue which is slung around the lower jaw. An internal

265 sheet of tissue divides the posterior quarter of the muscle from the anterior three-quarters.

266 Innervation: Trigeminal (V) nerve (Didier, 1995).

267 Remarks: In male holocephalans this muscle is functionally linked to the frontal tenaculum (Didier,

268 1995; Raikow and Swierczewski, 1975).

269 M. levator anguli oris posterior (Fig. 4b; m. lev. ang. oris post.)

270 Description: This muscle has an origin on the antorbital crest and preorbital fascia. It passes

271 ventrally over the $m$. adductor mandibulae anterior, inserting onto the connective tissue of the lip

272 between the premandibular and inferior maxillary cartilages via a tendon.

273 Innervation: Trigeminal (V) nerve (Didier, 1995).

274 Remarks:The extent of the origin of this muscle is variable in different genera (Didier, 1995). Didier

275 also reports an insertion on the supramaxillary cartilage - however, in our scans it appears to bypass

276 the cartilage medially, separated from it by the $m$. intermandibularis (Fig. 4c; m. intermand.).

277 M. levator anguli oris anterior (Fig. 4b; m. lev. ang. oris ant.) 
278 Description: This muscle, has an origin on the connective tissue attaching to the antorbital crest. It

279 inserts along the medial side of the anterior part of the superior maxillary cartilage. A bundle of

280 fibres, the M. levator anguli oris anterior pars rostralis (Fig. 4b; m. lev. ang. oris ant. pars. rost.),

281 extends anteriorly and inserts on the posterior side of the dorsal part of the prelabial cartilage. The

282 fibres of this portion are mixed with those of the $m$. levator anguli oris anterior posteriorly and with

283 those of the $m$. labialis anterior anteriorly.

284 Innervation: Trigeminal (V) nerve (Didier, 1995).

285 Remarks: In male holocephalans this muscle is functionally linked to the frontal tenaculum (Didier,

286 1995; Raikow and Swierczewski, 1975). Didier (1995) reported that the M. levator anguli oris

287 anterior pars rostralis inserted on the rostral rod in Callorhinchus. We find instead that it inserts on

288 the prelabial cartilage, consistent with the states that Didier reports in Rhinochimaera and

289 Chimaera. Anderson (2008) reports that in Hydrolagus fibres of this muscle insert into the

290 mandibular adductor muscles - we can find no evidence for this in Callorhinchus.

291 M. labialis anterior (Fig. 4c; m. lab. ant.)

292 Description: A small, thin muscle with an origin on the posterior side of the prelabial cartilage,

293 ventrally to the insertion of the $m$. levator anguli oris anterior pars rostralis. It inserts on the dorsal

294 process of and along the dorsal side of the superior maxillary cartilage.

295 Innervation: Trigeminal (V) nerve (Didier, 1995). 
Remarks: Didier (1995) reports that the origin of this muscle is instead on the anterior tip of the

297 prelabial cartilage. This is plausibly consistent with our data as the origin could feasibly wrap

298 around the element in thin connective tissue, but this not visible due to the resolution of our scan.

Description: A thin muscle with an origin along the posterior end and on the dorsal process of the

301 superior maxillary cartilage. It travels ventrally, and posteriorly to the inferior maxillary cartilage

302 has a marked posterior kink, corresponding to an internal sheet of tissue separating the muscle into

303 dorsal and ventral parts. It then travels posterior-ventrally where it is interrupted by an insertion on

304 the posterior and medial edges of the premandibular cartilage. It then continues anteriorly to insert

305 on the mandibular symphysis.

Innervation: Trigeminal (V) nerve (Didier, 1995).

Remarks: This muscle has been variously reported as two separate muscles (Edgeworth, 1902;

308 Kesteven, 1933; Luther, 1909a) $\square$, or a single muscle interrupted at the premandibular cartilage

309 (Didier, 1995) $\square$. Here we follow Didier, who puts forward plausible arguments that both of these

310 parts comprise the same muscle. At the premandibular cartilage where the two parts meet, there is

311 no clear distinction between them in our scan data.

312 M. superficialis (Fig. 4d; m. superfic.)

313 Description: This is a large, very thin muscle, the exact boundaries of which are extremely difficult

314 to make out in the scan data. However, it has a preorbital origin on connective tissue overlying the 
315 ethmoid crest. It then travels ventrally to insert along the upper lip, superficially relative to the

316 labial cartilages and all other mandibular muscles, and probably also in the rostrum (Didier, 1995).

317 Innervation: Trigeminal (V) nerve (Didier, 1995).

318 Remarks: Didier (1995) reports that this muscle is unique to Callorhinchus among chimaeroids.

319 M. constrictor operculi dorsalis (Fig. 4d, 5b; m. con. oper. dors.)

320 Description: A large, superficial muscle forming the opercular flap dorsal to the opercular cartilage.

321 Its origin is at the base of the scapular process, as well as in connective tissue which connects with

322 the notochord (see Didier, 1995) but which is difficult to resolve in our scan data. It inserts on the

323 rim of the operculum, in a mass of connective tissue above the opercular cartilage. The $\boldsymbol{M}$.

324 constrictor operculi dorsalis anterior (Fig. 4d, 6c; m. con. oper. dors. ant.) is a portion of this

325 muscle with an origin on the ventral rim of the orbit. It extends anteriorly via a tendon which splits

326 to insert on the jaw joint and in the connective tissue of the cheek. The boundary between these two

327 muscles is unresolvable in our scan data.

328 Innervation: Facial (VII) nerve (Didier, 1995).

329 Remarks: The $m$. constrictor operculi dorsalis anterior is only present in Callorhinchus amongst

330 chimaeroids (Didier, 1995).

331 M. constrictor operculi ventralis (Figs. 4d, 5c, 6c; m. con. oper. vent.) 
332

Description: A large superficial muscle in the ventral part of the opercular flap. Its origin is on the opercular cover, ventrally to the opercular cartilage. It wraps around the bottom of the head to insert ventrally to a fascia that joins it to its antimere. A muscle sheet also travels anteriorly, inserting in the connective tissues of the cheek, overlying the mandible and premandibular cartilage. A mesial sheet derived from the muscle travels dorsally to insert in the connective tissue of the $m$. mandibulohyoideus, posteriorly to Meckel's cartilage.

Innervation: Facial (VII) nerve (Didier, 1995).

Remarks: Like Didier (1995) we cannot find boundaries between the various component sheets of this muscle described by Kesteven (1933) and consider it to be a single muscle.

\section{M. levator hyoideus (Figs. 4a, 6a,b; m. lev. hyoid.)}

Description: This is a small, thin sheet of muscle, with an origin on the underside of the neurocranium, between the foraminae for the nervus hyoideo-mandibularis facialis and the nervus palatinus facialis. It inserts along the ventral part of the epihyal's postero-lateral edge. It is also linked by connective tissue to the opercular cartilage.

Innervation: Facial (VII) nerve (Didier, 1995)

M. mandibulohyoideus (Fig. 4a, 5a, 6a; m. mandibulohy.)

Description: This is a thin muscle with an origin on the posterior symphysis of the mandible, where it meets its antimere as well as the ventral constrictors via a tendon. It inserts on the ventral angle of the ceratohyal. 
Innervation: The facial (VII) nerve (Didier, 1995) as well as the glossopharyngeal (IX) nerve in

352 Hydrolagus (Anderson, 2008).

353

354

355

356

357

Remarks: Didier (1995) suggests that this muscle is correlated with the evolution of autostyly.

Kesteven (1933) called this muscle the geniohyoideus, while Didier (1995) called it the

interhyoideus. Anderson (2008) coined the name mandibulohyoideus for it to reflect the muscle's apomorphy with respect to the interhyoideus and geniohyoideus in osteichthyans, and this is the name we use here.

Mm constrictores branchiales. (Fig. 4b, 5a, 6c; mm. con. branch.)

Description: We find three branchial constrictor muscles. These are so small and thin as to be difficult to characterise, but their origins are high up on the lateral sides of epibranchials II and III, and on the lateral side of the posterior pharyngobranchial complex. Each extends antero-posteriorly onto the ventral side of the ceratobranchial of the anterior arch (i.e. ceratobranchials I-III).

Innervation: Glossopharyngeal (IX) and vagus (X) nerves (Didier, 1995).

Remarks: Like Didier (1995) we were unable to find the fourth branchial constrictor that Edgeworth (1935) described, however, the constrictor muscles are so thin that it is possible that it is unresolved in the scan data. Like Edgeworth (1935) reported, each constrictor passes between two arches. We agree with Didier that the ventral lengths of these muscles are likely described by Kesteven (1933) as possible transversi ventrales: "three long slender muscles, each of which arises from each of the first three basi-branchial cartilages and extends along the outer curve of the ceratobranchial of the same arch.”. Kesteven (1933) also describes three sets of "dorsal oblique interarcual muscles". Of these the "external dorsal oblique muscles" seem likely to be the dorsal part of the branchial 
372

373

375

376

377

378

379

380

381

382

383

384

385

386 constrictors on the basis of descriptions as a "short muscle which arises from the dorsal surface of the epibranchial of the fourth, third, and second arches, and is inserted on the top of the ceratobranchial of the third, second, and third arches".

Mm. interarcuales branchiales (Fig. 4a, 6a; mm. int. br.)

Description: These muscles are very small and extend from the ventral surface of the pharyngobranchials to the posterior edge of the epibranchials I-III.

Innervation: Glossopharyngeal (IX) and vagus (X) nerves (Didier, 1995; Edgeworth, 1935)

Remarks: These muscles are not mentioned by Didier (1995) but appear to roughly match the description of the external dorsal oblique muscles by Kesteven (1933), with the difference that they travel from pharyngobranchial to epibranchial rather than from epibranchial to ceratobranchial.

Mm adductores arcuum branchiales (Figs. 4a, 6b; mm. add. arc. br.)

Description: These muscles lie medial to the first four branchial arches, extending between the dorsal surface of the ceratobranchials and the ventral surface of the epibranchials. The origin of the first three is on epibranchials I-III, and they insert on ceratobranchials I-III. The fourth has two origins on the posterior pharyngobranchial complex (pharyngobranchials IV-V) and inserts on ceratobranchials IV-V. Also associated with the fourth is the M. constrictor oesophagi (Fig. 6b; $m$. con. oes.), the origin of which lies along the posterior process of the posteriormost pharyngobranchial, and which inserts along the postero-lateral length of the basibranchial copula. 
391 Remarks: These are probably the lateral internal dorsal oblique muscles of Kesteven (1933),

392 although our data shows them to insert high up on the epibranchial rather than on the

393 pharyngobranchials as described by Kesteven.

394 M. cucullaris superficialis (Fig. 4d; m. cuc. sup.)

395 Description: A large muscle with a broad origin on the postorbital crest and overlying the epaxial

396 muscles. It inserts on the scapular process, dorsal to the origin of the M. constrictor operculi

397 dorsalis.

398 Innervation: 4th branch of the Vagus (X) nerve (Edgeworth, 1935).

M. protractor dorsalis pectoralis (Fig. 4b; m. prot. dors. pect.)

Innervation: Glossopharyngeal (IX) and/or the vagus nerve (X) (Ziermann et al., 2014).

Remarks: There is some disagreement over whether this muscle is a trunk muscle or a branchial muscle (see Ziermann et al., 2014), which arises from uncertainty over the innervation.

M. cucullaris profundus (Fig. 4c; m. cuc. prof.) is a short, thin muscle. It has its origin on the underside of the otic region, lateral to the $M$. subspinalis. It inserts on the postero-ventral end of the posterior pharyngobranchial complex's lateral side, latero-ventral to the ceratobranchials. 
Innervation: 3rd branch of the vagus (X) nerve (Edgeworth, 1935).

411 Description: Broad and flat with an origin along a stretch of the otic shelf, medial to that of the $m$.

412 cucullaris profundus. It inserts along the dorsal surfaces of pharyngobranchials I and II.

413 Innervation: Spinal nerves, specifically the plexus cervicalis, formed by two or more anterior spinal 414 nerves (Edgeworth, 1935).

415 M. interpharyngobranchialis (Fig. 6b; m. interphar.)

416 Description: This is a very small muscle that joins the second pharyngobranchial to the posterior 417 pharyngobranchial complex.

418 Innervation: Spinal nerves, specifically the plexus cervicalis, formed by two or more anterior spinal 419 nerves (Edgeworth, 1935). Remarks: Edgeworth (1935) describes this muscle, while Didier (1995) describes it as absent. It is 421 of such a small size that it might be easily missed.

422 M. coracomandibularis (Figs. 4a, 5b, 6a,c; m. coracoma.)

423 Description: A very large muscle with its main origin on the T-shaped antero-ventral face of the 424 coracoid region of the pectoral girdle, and which inserts along Meckel's cartilage. Viewed ventrally 425 the muscles is triangular, broadening anteriorly. As described by Shann (1919) and Didier (1995) 
Innervation: Spinal nerves, specifically the plexus cervicalis, formed by two or more anterior spinal

the muscle is split into shallow and deep portions - the deeper portion inserts along the posterior of the mandible as a sheet, while the shallower portion splits into two thick bundles, which diverge about halfway along the muscles length to insert at either side of Meckel's cartilage. At its anterior extent the muscle is fairly flat, but towards the origin it develops a pronounced dorsal keel oriented postero-dorsally. This keel is cleft by a v-shaped septum, where the muscle splits into paired "arms" (Fig. 6a,c) that diverge laterally to origins on the left and right bases of the scapular processes, dorsal to the pectoral fin articulations.

Innervation: Spinal nerves, specifically the plexus cervicalis, formed from two or more anterior spinal nerves (Edgeworth, 1935).

Remarks: The morphology of this muscle varies in different holocephalan genera (Didier, 1995; Shann, 1919), particularly its relationship to the pectoral symphysis. Both Shann and Didier describe a v-shaped septum in the M. coracomandibularis of Chimaera, but report that this cannot be found in Callorhinchus. Our scan data shows it to be present, illustrated in our figures by the junction between the two colours of the muscle. As in Shann's description of Chimaera, the spinal nerves that innervate the $M$. coracomandibularis enter the muscle at this septum.

\section{M. coracohyoideus (Figs. 4a, 5a,6a,c; m. coracohy.)}

Description: A long thin muscle with its origin on the dorsal surface of the $M$. coracomandibularis, anteriorly to the V-shaped septum. It then extends anteriorly to insert on the posterior side of the basihyal.

nerves (Edgeworth, 1935) 
447 Remarks: Didier (1995) notes that it is unclear whether this muscle takes origin from the coracoid

448 or m. coracomandibularis in Callorhinchus. Our scan data shows that its entire origin lies on the $m$.

449 coracomandibularis (Fig. 4a).

450 Mm. coracobranchiales (Fig. 4b, 5a, 6c; mm. coracobr.)

451 Description: Long, thin muscles, with an origin along the dorso-lateral corner of the coracoid and

452 the base of the scapular process. They insert ventrally on the hypobranchials. The anterior three

453 attach to hypobranchials I-III, while the fourth and fifth attach to the fourth, posteriormost,

454 hypobranchial.

455 Innervation: Spinal nerves, specifically the plexus cervicalis, formed by two or more anterior spinal

456 nerves (Edgeworth, 1935).

Remarks: Although the muscles have separate heads, they are difficult to separate in our scan data

458 and have been segmented out together.

Description: Sheet-like muscle with origin on the top of the head, along the dorsal ridge and above

461 the orbit. It inserts posteriorly with the dorsal myomeres.

463 Remarks: Unlike in Scyliorhinus where the epaxials terminate posterior to the orbit, in

464 Callorhinchus they extend well anteriorly, terminating in front of the orbits. 
477 Description: This is a sheet of muscle. Its origin is in several places at the bottom of the scapular 478 process and on the posterior of the coracoid. It inserts in the lateral and ventral muscle of the body. 
Remarks: As above here is some disagreement over whether this muscle is a trunk muscle or a

481 branchial muscle (see Ziermann et al. (2014)).

M. rectus dorsalis (Fig. 3c; m. rect. dors.)

Description: This is antagonistic to the M. rectus ventralis. It has its origin in the orbit anteriorly to

484 the trigeminal nerve entrance. It inserts dorsally around the eye.

Innervation: Oculomotor (III) nerve (Edgeworth, 1935).

M. rectus ventralis (Fig. 3c ; m. rect. vent.)

Description: This muscle is antagonistic to the M. rectus dorsalis. It has its origin in the orbit anteriorly to the trigeminal nerve entrance, ventrally the profundus (V) nerve. It inserts ventrally around the eye, with a comparatively broad insertion. 
496

497

498

499

500

501

502

503

504

505

506

Innervation: Trochlear (IV) nerve (Edgeworth, 1935).

Innervation: Oculomotor (III) nerve (Edgeworth, 1935).

M. obliquus ventralis (Fig. 3c ; m. obl. vent.)

Innervation: Oculomotor (III) nerve (Edgeworth, 1935).

Description: This muscle has its origin relatively anteriorly to the other rectus muscles, and is antagonistic to the $M$. rectus lateralis. It inserts anteriorly around the eye.

Description: This muscle is antagonistic to the M. obliquus dorsalis. It has its origin just ventral to the antorbital crest, well anteriorly in the orbit. It inserts antero-ventrally around the eye.

Description: This muscle is antagonistic to the M. obliquus ventralis. It has its origin just medial to the antorbital crest, by the ophthalmic foramen. It inserts antero-dorsally around the eye.

$507 \quad$ Ligaments

508 Didier identifies two paired ligaments in the snout of Callorhinchus:

Ligamentum labialis (Fig. 2a; lig. lab.) 
510 Description: This travels between a dorsal process on the nasal capsule and then wraps around the

511 antero-ventral part of the prelabial cartilage.

512 Remarks: As Didier (1995) notes this is only present in Callorhinchus.

513 Ligamentum rostralis (Fig. 2a; lig. rost.)

514 Description: This travels between the dorso-anterior part of the prelabial cartilage onto the lateral

515 rostral rod.

516 Remarks: Didier (1995) notes this is only present in Callorhinchus.

517 ?Ligamentum pharyngohyoideus (Fig. 1d; ?lig. pharh.)

518 Description: A very small ligament (or possibly a slip of muscle) with an origin on the neurocranial

519 floor, posterior to the quadrate processes and lateral to the hypophyseal notch, and inserting on the 520 pharyngohyal dorsally.

521 Innervation: This is presumably innervated by the facial (VII) nerve, given its location, but no 522 precise innervation can be established.

523 Remarks: This structure has not been previously reported. Given that it has not been observed

524 before, and its poor visibility in the dataset, we are cautious its definite existence pending its

525 discovery in gross dissection. However, it is present on both sides of the dataset. Based on the

526 apparent lack of fibres we presume this is a ligament rather than a muscle, but the latter is certainly

527 not impossible. It may play a role in the operation of the operculum. 


\section{$528 \quad$ Scyliorhinus canicula}

\section{Cranial Cartilages}

530 The cranial skeleton of Scyliorhinus canicula comprises the neurocranium (Fig. 7), palatoquadrates,

531 Meckel's cartilages, two pairs of labial cartilages, the hyoid arch, and five branchial arches (Fig. 8).

532 As in other elasmobranchs the branchial skeleton stretches well-posterior to the neurocranium, 533 bounded posteriorly by ventrally joined scapulocoracoids.

534 The neurocranium in Scyliorhinus is fairly flat, with large orbits and broad ethmoid and otic

535 regions. The olfactory capsules are subspherical and very large, taking up about a third of the

536 volume of the entire neurocranium. Ventrally they are open and partially covered by digitate and

537 scrolled projections of cartilage (Fig. 7a, scr. cart.). They are separated by a medial wall of cartilage

538 which expands ventrally into a narrow internasal plate (Fig. 7a, intn. pl.). Anteriorly the olfactory

539 capsules are marked by shallow depressions, in which an anterior grouping of the ampullae of

540 Lorenzini sits (Fig. 7d, ant. Lor.). This structure is supported by three rostral rods (Fig. 7b, rost. rod

541 m., 1.), one unpaired ventrally and one paired dorsally, which curve, converging centrally. Between

542 the two olfactory cartilages dorsally a large precerebral fontanelle is situated (Fig. 7b, d, pre. font.).

543 The orbits are large and oval, comprising about half of the length of the neurocranium. Dorsally

544 they are bounded by a strong supraorbital ridge (Fig. 7b, suporb. ridge), with sharp anterior and

545 posterior terminations. Posteriorly this forms the postorbital process (Fig. 7c, postorb. proc.) which,

546 like in other elasmobranchs, does not extend ventrally to form a postorbital arcade. Between the

547 orbits the roof of the neurocranium rises to form a shallow ridge, the apex of which is incompletely

548 chondrified (Fig. 7b, unchond.). Between this and the supraorbital ridges are a pair of shallow

549 furrows carrying ampullae of Lorenzini (Fig. 7b, lat. Lor.), which are innervated by twigs of the 
550

superficial ophthalmic complex through foraminae in the supraorbital ridge (Fig. 7b., supoph. for.).

The main trunk of the superficial ophthalmic complex enters the orbit through a large foramen postero-dorsally (Fig. 9a; supoph. for. post.). A small foramen next to this permits the entry of the profundus into the orbit (Fig. 9a; prof. for.). The superficial ophthalmic complex and profundus exit the orbit together passing through a large foramen in the dorso-anterior corner onto the anterior neurocranial roof (Figs. 7b, 9a; supoph. for. ant.). Posterior to this, high up on the wall of the orbit is a small foramen through which the abducens (IV) nerve enters the orbit (Fig. 9a; abd. (IV) for.) (Holmgren, 1940). Ventrally the orbit is bounded by a broad suborbital shelf (Fig. 7a, suborb. shelf). In the postero-ventral corner of the orbit is a large foramen through which the facial (VII) and trigeminal (V) nerves enter the orbit (Fig. 9a; V+VII). Ventro-laterally to this is a small foramen through which the orbital artery enters the orbit (Fig. 9a; orb. art.). Antero-dorsally to the facial and trigeminal nerve foramen is an opening for the oculomotor (III) nerve (Fig. 9a; oculom. (III) for.) (Holmgren, 1940), while anteriorly to it is a foramen for the pituitary vein (Fig. 9a; pit. v.) (Holmgren, 1940). Anteriorly to this is a foramen for the efferent pseudobranchial artery (Fig. 9a; eff. pseud.), and anteriorly to this the foramen for the optic (II) nerve (Fig. 9a; opt. (II) for.) as well as the optic artery. A small foramen antero-dorsal to the foramen for the optic nerve permits entry for the anterior cerebral vein (Fig. 9a; ant. cer. v.). A foramen in the antero-ventral corner of the orbit provides an entry for the nasal vein through the orbitonasal canal (Fig. 9a; orbnas. can.). Posteriorly to the orbit on the skull roof is a large foramen, through which the postorbital sensory canal passes (Fig. 7, post. can. for.).

The otic capsules are broad and marked by a dorsal ridge formed by the anterior and posterior semicircular canals, with the external semicircular canal forming a pronounced lateral ridge. Below the lateral ridge is a marked groove for the jugular vein (Fig. 7c, jug. groove). Anteroventrally to this lies a flat surface on which the hyomandibula articulates (Fig. 7c, hyomand. art.). Posteriorly to this jugular groove is the exit point of the glossopharyngeal (IX) nerve canal (Fig. 7e, gloss. (IX) 
575

576

577

578

579

580

581

582

583

584

585

586

587

588

589

590

591

592

593

594

595

596

597

can.). Between the dorsal ridges is a shallow endolymphatic fossa (Fig. 7b, endo. fossa), containing paired openings - a larger pair for the endolymphatic ducts (Fig. 7b, endo. duct) and a smaller pair antero-laterally for the perilymphatic ducts (Fig. 7b, peri. duct). Posteriorly to these are paired occipital processes that join to form an arc (Fig. 7b, c, occ. proc.). A rounded foramen magnum (Fig. 7e, for. mag.) is positioned below this, and ventrally to this is a shallow occipital cotylus (Fig. 7e, occ. cot.), bounded laterally by rounded occipital condyles (Fig. 7e, occ. cond.). Laterally to these are a pair of foraminae for the exit of the Vagus (X) nerve canal (Fig. 7e, vagus (X) can.). At least one of the spinal nerves appears to join the Vagus to leave through the vagal canal: the rest diverge posteriorly to the braincase.

The ventral side of the neurocranium is flat, broad, and fairly featureless. At about one third of the length from the posterior it is punctured by a medial foramen through which the internal carotids enter the neurocranium (Fig. 7a, int. car. for.), and lateral to this are paired foraminae through which the orbital arteries enter the orbits (Fig. 7a; orb. art.).

Scyliorhinus also possesses a small prespiracular cartilage, in the anterior wall of the spiracle (Ridewood, 1896, Tomita et al. 2018). However, resolution surrounding the spiracle in our dataset proved insufficient to locate this.

The palatoquadrates (Fig. 8a, b; palatoq.) are about one third of the length of the neurocranium and joined at an anterior symphysis. They are low and flat, with a short, rounded ethmoid process on the medial face of the palatine process, via which the neurocranium is joined to the palatoquadrate by the ethmopalatine ligament (see below) (Fig. 8e; eth. proc.). Anteriorly to this process the dorsal edge is marked by a shallow groove. The inside edge carries a shallow sulcus for the teeth (Fig. 8c; dent. sulc.). Meckel's cartilages are about one and a half times as deep as the palatoquadrates (Fig. 8a, b; Meck.), and are joined at an anterior symphysis. Dorsally it is grooved 
by a sulcus for the attachment of teeth (Fig. 8c; dent. sulc.). It is ventrally tall, particularly along its posterior half before abruptly losing height. A dorsal and a ventral pair of labial cartilages are

600 positioned lateral to the jaws, which together form a v-shape with the open end anteriorly (Fig. 8a,

601 b; lab. d., lab. v.). The elements have a double-articulation. A large medial process (Fig. 8d; med.

602 proc.) and lateral fossa (Fig. 8d; lat. foss.) on Meckel's cartilage articulate with a narrow lateral

603 process (Fig. 8e; lat. proc.) and shallow medial fossa (Fig. 8e; med. foss.) on the palatoquadrate.

604 The hyoid arch comprises a basihyal, and paired ceratohyals and hyomandibulae (epihyals). The

605 basihyal is broad and flat (Fig. 8f; basihy.), and is punctured centrally by a single foramen for the 606 thyroid gland stalk (De Beer and Moy-Thomas, 1935). A rim curves around its anterolateral edge,

607 and terminates posteriorly, forming paired ceratohyal articulations along with posteriorly projecting

608 paired processes. The ceratohyal (Fig. 8f; ceratoh.) is laterally flattened and curved dorsally. The

609 anterior end is expanded into two heads, the anterior of which articulates in the basihyal's fossa.

610 The hyomandibula (Fig. 8f; hyomand.) is short and stout, with expanded ends for the articulation

611 with the braincase and the ceratohyal. It articulates on the ventral side of the otic capsule,

612 immediately posterior to the orbit. Hyoid rays (Fig. 8f; hyo. ray) are attached to the posterior side of

613 the hyomandibula and ceratohyal, and form a branching series of rays that support the first gill flap.

614 Posterior to the hyoid arch are five branchial arches. The floor of the pharynx is supported by a

615 basibranchial copula and four hypobranchials. The basibranchial copula (Fig. 8f; cop.) is a large,

616 flat, posteriorly located element with a posterior tail, the posterior length of which is mineralised.

617 The anteriormost hypobranchial (Fig. 8f; hbr.) is small and cuboid, and oriented anteriorly,

618 overlying the ceratohyal and joining the posterior process of the basihyal to the first

619 ceratobranchial. The posterior three hypobranchials are long and thin, each smaller than the one

620 before, and are oriented posteriorly towards the anterior edge of the copula from the junction

621 between the first and second, second and third, and third and fourth ceratobranchials. The first four 
622 ceratobranchials (Fig. 8f; cbr.) are long and thin, and their distal end is expanded into two heads,

623 each of which meets the hypobranchial and ceratobranchial of the arches in front and behind. The

624 dorsal proximal surface is marked by a deep spoon-shaped concavity in which the branchial

625 adductor muscles sit, and which is pierced by a foramen, possibly to allow vascularization or

626 innervation of the adductor muscles. The posteriormost ceratobranchial is broad and flat, lacks a

627 distal head, and has its proximal end branched into two parts. The first four epibranchials (Fig. 8f;

628 ebr.) are short and rectangular with a short anterior process, and concave ventrally for the branchial

629 adductors. They are pierced by a foramen, again possibly for the vascularization or innervation of

630 the branchial adductors. There are three separate pharyngobranchials (Fig. 8f; pbr.), which are long,

631 thin arrowheads swept posteriorly. Their proximal ends are expanded in two heads, the anterior one

632 of which articulates with the anterior epibranchial and the posterior one of which overlies the

633 epibranchial behind. The posteriormost pharyngobranchial(s) and the fifth epibranchial are fused

634 into a single pick-shaped posterior complex (Fig. 8f; post. comp.) with an anterior process

635 articulating with the fourth epibranchial, a ventral process articulating with the fifth ceratobranchial,

636 and a posterior swept back process. The branchial rays (Fig. 8a; br. ray) are unbranched, unlike

637 those of the hyoid, and attached to the ceratobranchials and epibranchials of the first four branchial

638 arches, becoming less numerous on posterior arches. Five dorsal extrabranchial cartilages (Fig. 8a;

639 exbr. d.) overlie each gill flap, with heads on the lateral face of the expaxial (I) and cucullaris (II-V)

640 muscle. There are three ventral extrabranchial cartilages (Fig. 8a; exbr. v.), supporting the second,

641 third, and fourth gill flaps ventrally. These have complex-shaped heads that are ventrally inserted

642 between the coracobranchial muscles and over lying the coracoarcual muscles.

\section{Cranial Muscles}

644 This account follows the terminology of Edgeworth (1935). 
646 Description: A long thin muscle with its origin on the posterior part of the nasal capsule,

647 immediately antero-lateral to the orbit. It extends postero-ventrally to insert in the fibres of the

648 dorsal part of the adductor muscle. It is separated from the M. adductor mandibulae by the

649 trigeminal $(\mathrm{V})$ nerve, which lies across the lateral surface, but the border between the fibres of the

650 two muscles are largely indistinguishable in our scan data and are segmented as one model. Fibres

651 of the m. levator labii superioris reach the level of the fascia separating the dorsal and ventral parts

652 of the mandibular adductor.

653 Innervation: Trigeminal (V) nerve (Edgeworth, 1935).

654 Remarks: This muscle is variable in galeomorph sharks, with phylogenetic significance (See 655 discussion in Soares and Carvalho, 2013 $\square$ ).

656 M. adductor mandibulae (Figs. 10a, 11a; m. add. mand.)

657 Description: This muscle is divided into two parts, dorsal and ventral, and is separated from the $M$.

658 levator labii superioris by the trigeminal (V) nerve. Dorsal and ventral parts are separated by an

659 internal fascia, latero-ventral to the mandibular joint, on which they both insert. The origin of the

660 dorsal part occupies a shallow fossa in the posterior third of the palatoquadrate's lateral face. The

661 origin of the ventral part occupies a shallow fossa in the posterior half of the lateral face of

662 Meckel's cartilage.

663 Innervation: Trigeminal (V) nerve (Edgeworth, 1935). 
664 M. intermandibularis (Figs. 10c, 11c, 12c; m. intermand.)

665 Description: This is a broad, flat, triangular muscle with its origin along the posterior margin of the

666 Meckelian cartilages. It then extends posteriorly as a sheet, inserting medio-ventrally on the

667 aponeurosis of the $m$. constrictor hyoideus.

668 Innervation: Trigeminal (V) nerve (Edgeworth, 1935).

669 Remarks: The exact point of insertion is difficult to see in our scan data because it is so thin, but it

670 matches accounts of the same muscle in other elasmobranchs (Soares and Carvalho, 2013;

671 Ziermann et al., 2014).

672 M. levator palatoquadrati (Fig. 10a; m. lev. pal.)

673 Description: A thin muscle with an origin on the latero-ventral side of the otic process, immediately

674 posterior to the postorbital process and ventral to the neurocranial roof. It inserts on the medial side

675 of the palatoquadrate, just anteriorly to the jaw joint, in a shallow depression.

676 Innervation: Trigeminal (V) nerve (Edgeworth, 1935).

677 M. levator palpebrae nictitantis (Fig. 10b; m. lev. palp. nict.)

678 Description: A thin muscle, overlying the m. levator palatoquadrati. It has its origin on the on the

679 dorso-lateral corner of the otic process, dorso-posteriorly to the origin of the m. levator

680 palatoquadrati and extends antero-ventrally to insert on the lower eyelid. 
681 Innervation: Trigeminal (V) nerve (Edgeworth, 1935).

682 M. retractor palpebrae superioris (Fig. 10b; m. ret. palp. sup.)

683 Description: This is a short, fat muscle overlying the $m$. levator palpebrae nictitantis. It has its

684 origin on the otic region, ventral to the origin of the m. levator palpebrae nictitanis. It travels dorso-

685 anteriorly, overlying the $m$. levator palpebrae nictitantis and inserting on the upper eyelid.

686 Innervation: Trigeminal (V) nerve (Edgeworth, 1935).

687 Remarks: This matches the accounts of Ridewood (1899) and Edgeworth (1935) and is unlike data

688 in Soares and Carvalho (2013) who imply that Scyliorhinus has both a m. retractor palpebrae

689 superioris and a m. depressor palpebrae superioris.

690 M. constrictor hyoideus dorsalis (Fig. 10c; m. con. hy. dors.)

691 Description: This is a large thin muscle with a broad origin extending from over the anteriormost $m$.

692 constrictor superficiales and anteriorly over the lateral side of the m. epaxialis. The muscle overlies

693 the eyelid muscles and has a further origin on the lateral wall of the otic capsule. The anterior part

694 of the muscle inserts along the postero-ventral two thirds of the hyomandibula, while posteriorly it

695 overlies the hyoid rays, inserting in the dorsal fibres of the $m$. constrictor hyoideus ventralis.

696 Innervation: Facial (VII) nerve (Edgeworth, 1935). 
Remarks: This muscle includes the m. levator hyomandibulae (the anterior fibres), which are

698 inseparably joined (Soares and Carvalho, 2013). Exact boundaries were difficult to segment out due

699 to the muscle's small width.

711 Description: These are small muscles of which there are five. They have their origin on spoon-

712 shaped fossae on the dorsal surface of each ceratobranchial and insert in shallow fossae in the

713 ventral surface of each corresponding epibranchial. The fifth inserts on the posterior

714 pharyngobranchial complex. 
715 Innervation: Vagus (X) and glossopharyngeal (IX) nerves (Edgeworth, 1935).

716 Remarks: Unlike the Callorhinchus there is one muscle per branchial arch.

717 Mm. arcuales dorsales (Figs. 10a, 12a; m. arc. dors.)

718 Description: There are four of these muscles. They have their origin on the lateral surfaces of 719 epibranchials I-IV, and insert on the ventro-lateral edge of each pharyngobranchial, between their 720 anterior and lateral processes.

721 Innervation: Vagus (X) and glossopharyngeal (IX) nerves (Edgeworth, 1935).

722 Remarks: Allis (1917) refers to these as the Mm. arcuales. We have used Edgeworth's name for 723 clarity.

724 Mm. constrictor superficiales (Figs. 10c, 11b, 12c; mm. con, sup.)

725 Description: These are very thin sheet-like muscles. They have their origin medially to the $m$.

726 cucullaris profundus, where they insert between the dorsal extrabranchial cartilages. They travel

727 ventrally to the gill bars, and insert ventrally into the medial aponeurosis.

728 Innervation: Vagus (X) and glossopharyngeal (IX) nerves (Edgeworth, 1935).

729 M. subspinalis (Figs. 10a, 12a,c; m. subspin.) 
Description: A thin flat muscle with an origin on the postero-ventral edge of the neurocranium,

731 ventral to the occipital condyle, as well as on the ventral side of the spinal column. It then passes

732 posteriorly and inserts on the medial tip of pharyngobranchial I.

733 Innervation: Spinal nerves, specifically the plexus cervicalis, formed from two or more anterior

734 spinal nerves (Edgeworth, 1935).

735 Mm. interpharyngobranchiales (Figs. 10a, 12a; Mm. interphar.)

736 Description: These pass between the pharyngobranchials and are three in number.

737 Innervation: Spinal nerves, specifically the plexus cervicalis, formed from two or more anterior 738 spinal nerves (Edgeworth, 1935).

M. coracomandibularis (Figs. 10a, 11b, 12b,c; m. coracoma.)

740 Description: This is a long thin muscle. It has its origin on the posterior part of Meckel's cartilage,

741 and runs posteriorly to insert with the $m$. coracohyoideus and m. coracobranchiales muscles

742 ventrally (on the aponeurosis of the $m$. constrictor hyoideus centralis).

743 Innervation: Spinal nerves, specifically the plexus cervicalis, formed from two or more anterior

744 spinal nerves (Edgeworth, 1935).

745 M. coracohyoideus (Figs. 10a, 11a, 12b,c; mm. coracohy.) 
746 Description: This is a long thin muscle. It has its origin on the ventral surface of the basihyal, and

747 extends postero-ventrally to attach ventrally (on the aponeurosis of the $m$. constrictor hyoideus

748 centralis).

749 Innervation: This is innervated by spinal nerves, specifically the plexus cervicalis, formed by two

750 or more anterior spinal nerves (Edgeworth, 1935).

751 Remarks: Edgeworth calls this the rectus cervicis but for consistency we have kept it as $m$.

752 coracohyoideus.

753 Mm coracobranchiales (Figs. 10a, 11a, 12b,c; mm. coracobr.)

754 Description: These are five in number. The first has its origin anterior to the first ceratobranchial's

755 ventral tip. This pattern continues posteriorly with the II-IV. The Vth one has its origin on

756 ceratobranchial V and the copula. Number I inserts at the medial part with the coracohyoid and

757 mandibular. II-V insert on the coracoid process of the scapulacoracoid.

758 Innervation: Spinal nerves, specifically the plexus cervicalis, formed from two or more anterior

759 spinal nerves (Edgeworth, 1935).

761 Description: is a large triangular muscle divided into two parts by an internal septum. The anterior 762 part has its origin in the anterior musculature, between the hyoid constricor and the epaxial muscles.

763 It inserts on the posteriormost epibranchial. The posterior part inserts along the length of the

764 scapular process. 
Description: A short broad muscle with an origin on the anterior face of the ventral symphysis of

768 the shoulder girdle. It inserts on the ventral aponeurosis, between the $m$. coracohyoideus and the $m$.

769 coracobranchiales.

770 Innervation: Spinal nerves (Edgeworth, 1935).

$771 \quad$ M. epaxialis (Figs. 10b; m. epax.)

772 Description: Segmented muscles with an origin on the posterior part of the dorsal surface of the

773 neurocranium, in broad fossae over the otic capsule. It inserts posteriorly with the dorsal myomeres.

774 Innervation: Spinal nerves (Edgeworth, 1935).

775 M. rectus dorsalis (Fig. 9b; m. rect. dors.)

776 Description: This is antagonistic to the M. rectus ventralis. It has its origin in the posterior part of

777 the orbit, antero-dorsally to the foramen for the V+VII nerves and below the entry for the

778 superficial ophthalmic complex. It inserts dorsally over the eye.

779 Innervation: Oculomotor (III) nerve (Edgeworth, 1935). 
781 Description: This is antagonistic to the M. rectus dorsalis. It has its origin immediately posterior to

782 the former's origin, above the foramen for the V+VII nerves. It inserts ventrally around the eye.

783 Innervation: Oculomotor (III) nerve (Edgeworth, 1935).

784 M. rectus lateralis (Fig. 9b; m. rect. lat.)

785 Description: This is antagonistic to the M. rectus medialis. It has its origin in the orbit ventrally to

786 that of the M. rectus ventralis trigeminal nerve entrance. It inserts posteriorly around the eye.

787 Innervation: Abducens (VI) nerve (Edgeworth, 1935).

788 M. rectus medialis (Fig. 9b; m. rect. med.)

789 Description: This has its origin relatively anteriorly to the other rectus muscles and is antagonistic

790 to the M. rectus lateralis. It inserts anteriorly around the eye.

791 Innervation: Oculomotor (III) nerve (Edgeworth, 1935).

792 M. obliquus ventralis (Fig. 9b; m. obl. vent.)

793 Description: This is antagonistic to the M. obliquus dorsalis. It has its origin anterior to the foramen

794 for the IV nerve. It inserts antero-ventrally around the eye.

795 Innervation: Oculomotor (III) nerve (Edgeworth, 1935). 
Description: This is antagonistic to the M. obliquus ventralis. It has its origin just dorsal to that for the M. obliquus ventralis. It inserts antero-dorsally around the eye.

Innervation: Trochlear (IV) nerve (Edgeworth, 1935).

\section{$800 \quad$ Ligaments}

801 Ethmopalatine ligament (Fig. 8a; lig. ethpal.)

802 Description: This ligament links the palatoquadrate to the neurocranium. It attaches onto the

803 posterior part of the nasal capsule and the anterior part of the suborbital shelf. It extends to attach on

804 the anterior side of the ethmoid process of the palatoquadrate.

805 Mandibulohyoid ligament (not figured)

806 In elasmobranchs a ligament binds the hyoid arch to the mandible (Wilga et al. 2000). However,

807 contrast is insufficient to model this out in our scan data.

808 Superior and inferior spiracular ligaments (not figured)

809 In Scyliorhinus two ligaments associated with the spiracle link the ceratohyal and hyomandibula to

810 the neurocranium (Ridewood, 1896). However, the contrast around the spiracle is insufficient to 811 model these in our data. 


\section{Discussion}

813 The very different cranial constructions of Callorhinchus and Scyliorhinus are reflected in two very

814 different arrangements of cranial muscles. In Callorhinchus and other holocephalans, muscles are

815 arranged to accommodate an anteriorly placed mandible, extensive labial cartilages, and a

816 subcranial pharynx (Didier, 1995). In Scyliorhinus and other elasmobranchs they are instead

817 arranged around a hyostylic jaw suspension and elongated pharynx, with some variation within the

818 group, particularly in the areas of the eyelid muscles and jaws(Soares and Carvalho, 2013). The

819 evolution of these two divergent morphologies can be traced back to the origins of the two clades in

820 the Paleozoic, using the fossil record of early members of crown-group and stem-group

821 Chondrichthyes, which preserve evidence of muscle morphology and attachments in the form of

822 skeletal correlates and (very rarely) fossilised muscles. Assessing the relative evolution of these two

823 types is somewhat hindered by the poorly understood phylogenetic relationships of early members

824 of the chondrichthyan crown- and stem-groups. Nonetheless, below we assess the relationships of

825 muscles in the living taxa described above to those seen in their fossil relatives.

\section{The evolution of chondrichthyan jaw musculature}

827 Chondrichthyan jaw suspensions, around which jaw muscles are arranged, show a wide array of

828 anatomies (Maisey, 1980), all of which likely derive from a common form seen in Paleozoic sharks.

829 Variations in suspensory anatomy center around the palatoquadrate's points of articulation with the

830 neurocranium as well as the role of the hyoid arch in suspension. A prevalent idea amongst early

831 vertebrate workers was that all gnathostome jaw suspensions derive from autodiastyly: an

832 arrangement where the palatoquadrate is suspended from the neurocranium by otic and basal

833 articulations and the hyomandibula is non-suspensory, a form from which in theory all gnathostome 
834 jaw suspensions can be derived (De Beer and Moy-Thomas, 1935; Grogan et al., 1999; Grogan and

835 Lund, 2000). Autodiastyly was originally hypothetical and does not exist in any living vertebrate,

836 although comparisons have been drawn with holocephalan embryos (Grogan et al., 1999) and a

837 comparable arrangement exists in the Paleozoic stem-holocephalan Debeerius (Grogan and Lund,

838 2000). However, fossil morphologies in current phylogenetic topologies do not support the idea that

839 this is the chondrichthyan ancestral state. Maisey $(1980,2001,2008)$ argued that an autodiastylic

840 chondrichthyan common ancestor was unlikely based on the prevalence of suspensory hyoid arches

841 across the gnathostome crown-group, as well as the suspensory hyoid arch and postorbital

842 articulation of the palatoquadrate in Pucapampella, likely a stem-chondrichthyan. Since then this

843 position has been strengthened as the chondrichthyan stem-group has been populated by several

844 other taxa, including Gladbachus, Doliodus, and Acanthodes, all of which possess a postorbital

845 articulation and a suspensory hyoid arch (Maisey et al., 2009; Brazeau and de Winter, 2015; Coates

846 et al., 2018). The identification of symmoriiformes, which also have a hyomandibula articulating on

847 the neurocranium and a postorbital articulation of the palatoquadrate, as stem-holocephalans further

848 supports this (Coates et al., 2017), although the possibly reduced role of the hyoid arch in jaw

849 suspension may be a precursor to the holocephalan state (Pradel et al., 2014). All this evidence

850 points towards the holocephalan jaw suspension being derived from an ancestral state with ethmoid

851 and postorbital articulation in what Maisey (2008) terms archaeostyly.

852 As a result of this the divergent mandibular adductor musculature morphologies of holocephalans

853 and elasmobranchs presumably derives from a more elasmobranch-like model. In Callorhinchus

854 and other holocephalans the mandibular adductors are located almost entirely preorbitally, directly

855 linking the neurocranium and the lower jaw (Fig. 3; Didier, 1995). In elasmobranchs they instead lie

$856 \mathrm{post} / \mathrm{suborbitally}$ and attach to the mandibular cartilages laterally. Anderson (2008) notes that the

857 holocephalan condition has similarities with that of the osteichthyan Amia, with a neurocranial

858 origin of the mandibular adductors and an insertion on tissue slung around the ventral side of the 
859

860

861

862

863

864

865

866

867

868

869

870

871

872

873

874

875

876

878

879

880

881

882

883

mandible. However, in chondrichthyans this is certainly the more derived of the two conditions:

stem-chondrichthyans such as Acanthodes and Gladbachus, as well as early crown-chondrichthyans such as Tristychius and Akmonistion, lack an anteriorly restricted mandible, and possess clear fossae for a mandibular adductor spanning the lateral sides of the mandibular cartilages as in elasmobranchs, and dorsally restricted by rims precluding attachment on the neurocranium (Coates et al., 2019, 2018; Coates and Sequeira, 2001; Miles, 1973). An Upper Devonian cladoselachian preserving palatoquadrates and parts of this mandibular adductor is also consistent with this morphology (Maisey, 1989). Based on the broad presence of this arrangement across chondrichthyan phylogeny the holocephalan condition can only be interpreted as derived.

Labial muscles are present in both holocephalans and elasmobranchs, but the homologies between the two are uncertain. In holocephalans labial muscles take the form of the suite of preorbital muscles inserting on the labial cartilages: the mm. anguli oris and the m. labialis. In elasmobranchs they comprise the m. levator labii superioris (or preorbitalis), which links the palatoquadrate to the neurocranium anteriorly, and which varies in its attachment to the neurocranium in different groups (Wilga, 2005). Anderson (2008) argued that these muscles are homologous on the basis that they are both preorbital facial muscles with a trigeminal (V) innervation that insert, at least in part, on the mandible (although we found no evidence for such an insertion in Callorhinchus). Unfortunately, corroborating evidence in stem-group and early crown-group chondrichthyans is limited. Although a labial muscle has been reconstructed in Acanthodes and Cladodus (Lauder, 1980), this is not on the basis of any positive fossil evidence - the muscle leaves no clear skeletal attachment areas, and is not observable in cladoselachian specimens preserving muscles (Maisey, 2007, 1989). If they are homologous, the shift to a holocephalan-like insertion on the labial cartilages is presumably linked to the evolution of extensive labial cartilages and holostyly, so would likely have taken place at some point in the stem-group after the divergence of symmoriiforms, However, it remains difficult to see a clear skeletal correlate. 
884 However, the morphology of fossil holocephalan neurocrania does provide some clues and

885 constraints on when their preorbital mandibular muscle morphology arose. Mesozoic stem-group

886 holocephalans - Acanthorhina, Chimaeropsis, Metopacanthus, Squaloraja, and Isychodus - are

887 reconstructed with skulls with a large rostrum, shaped in such a way as to allow attachment of

888 preorbital mandibular musculature, although their flattened skulls make this difficult to know

889 definitively (Patterson, 1965). Moreover, the Paleozoic holocephalan Chondrenchelys is interpreted

890 as having had adductor muscles that attached preorbitally on the basis of the morphology of its

891 preorbital region (Finarelli and Coates, 2014). As Finarelli and Coates (2014) highlight, an

892 anteriorly restricted mandible and ventral gill skeleton are not present in Chondrenchelys,

893 suggesting that the preorbital attachment of mandibular adductors preceded these shifts. Debeerius

894 also possesses a large rostral region, although Grogan and Lund (2000) interpret the adductor

895 muscles as having attached on the posterior part of the palatoquadrate. Providing a lower boundary

896 on the morphology are the more shark-like stem-holocephalans such as symmoriiformes, which

897 have neurocrania and jaws incompatible with a crown-holocephalan-like configuration (see above).

898 Several edestids have enlarged rostra (most obviously Ornithoprion; Zangerl, 1966), but also

899 separate palatoquadrates with posteriorly located adductor muscles (see Helicoprion; Ramsay et al.,

900 2015). This suggests that the development of a large ethmoid region in the holocephalan stem-group

901 preceded the fusion of the palatoquadrates with the neurocranium and the shift of the adductor

902 muscles onto the neurocranium, which took place somewhere between the divergence of edestids

903 and Chondrenchelys from the crown-lineage.

904 A curious exception that does not fit this pattern is iniopterygians, another member of the

905 holocephalan stem-group. Like in living holocephalans this group possesses anteriorly placed

906 Meckel's cartilages with a medial symphysis, palatoquadrates fused to the neurocranium (in some

907 members), and a subcranial branchial skeleton (Pradel, 2010; Pradel et al., 2009). As three-

908 dimensional specimens of "Iniopera" show, the large orbits would have obstructed a postorbital 
909

910

911

912

913

914

915

916

917

918

919

920

921

922

923

924

925

926

927

928

929

930

931

932

933

attachment of the adductor muscles (Pradel, 2010; Pradel et al., 2009). However, a large rostral

surface for a preorbital attachment of the adductor muscles is decidedly absent. Instead a very

shallow fossa above the quadrate articulation in the suborbital shelf provides a possible attachment point (Pradel, 2010; fig. 6,11), as does the small preorbital surface (Pradel, 2010; fig. 6). If two

mandibular adductors were present, as in Callorhinchus, it is possible that the fossa in the orbit

provided attachment for the posterior mandibular adductor while the anterior mandibular adductor attached preorbitally. Notably "Iniopera" also possesses ventrally delimited fossae on the postero-

lateral sides of the Meckel's cartilages, possibly to house the ventral adductor (Pradel, 2010; figs.

31, fam), suggesting the muscles were not slung ventrally around the jaw as in living

holocephalans. Whether this set of traits is homologous with crown-holocephalans or a homoplasy

linked to iniopterygians derived form is unclear. However, iniopterygians do demonstrate that once holostyly and anteriorly-placed adductor muscles had evolved, a large-rostrumed holocephalan-like form was not an inevitability for holostylic holocephalans.

As well as the facial muscles, the large coracomandibularis is an unusual feature of the holocephalan mandibular musculature. In both holocephalans and elasmobranchs, the lower jaw is depressed by the coracomandibularis muscle, unlike in osteichthyans which use the coracohyoideus to transmit movement through the mandibulohyoid ligament (Anderson, 2008). A chondrichthyanlike arrangement was also present in mandibulate stem-gnathostomes, and so is likely the ancestral state for crown-group gnathostomes (Johanson, 2003). However, within chondrichthyans the coracomandibularis of holocephalans (e.g. Callorhinchus, Fig. 4) is far larger than that of Scyliorhinus and other chondrichthyans and attaches over a greater area both on the shoulder girdle and on the mandible. Again, evidence for the presence of this muscle is limited in the holocephalan stem-group, but it seems likely to be part of the suite of adaptations linked to durophagy and a ventrally located pharynx. In the stem-holocephalan Iniopera the shoulder girdle and mandible have an extremely close association (Pradel pers. obs.) possibly placing the evolution of a large, short 
934 coracomandibularis as far back in the holocephalan stem-group as crown-holocephalans' divergence

935 from iniopterygians.

\section{Pharyngeal muscles}

937 The non-suspensory nature of the holocephalans hyoid arch as well as its supposed

938 "morphologically-complete" nature has been used to argue that they represent the primitive

939 gnathostome condition (Grogan and Lund, 2000), but both are likely derived. Maisey (1984)

940 outlined why the holocephalan condition is unlikely to be plesiomorphic for chondrichthyans on the

941 basis of a convincing set of anatomical arguments. This included the fact that the holocephalan

942 hyoid arch is bypassed by the branchial muscles linking the dorsal branchial series, the condition

943 we see in Callorhinchus. In stem-chondrichthyans such as Gladbachus and Acanthodes the

944 hyomandibula articulates directly with the neurocranium and lacks a pharyngohyal (Brazeau and de

945 Winter, 2015; Coates et al., 2018), and the same state is seen in shark-like putative stem-

946 holocephalans (e.g. Ozarcus; Pradel et al., 2014) strongly suggesting that this condition is

947 plesiomorphic for the chondrichthyan crown-group. This implies that hypotheses based on the idea

948 that the holocephalan branchial skeleton and jaw articulation are primitive are incorrect, and it

949 seems likely that a more elasmobranch-like arrangement is primitive for chondrichthyans. If

950 autapomorphic the holocephalan pharyngohyal is perhaps instead linked to the holocephalan hyoid

951 arch's role in supporting the roof of the pharynx, or with the role it plays in supporting the

952 operculum. The ligament we report linking the pharyngohyal to the basicranium may anchor the

953 hyoid arch to the neurocranium for one (or both) of these purposes.

954 Although both holocephalans and elasmobranchs possess a coracomandibularis, linking mandible

955 and shoulder girdle, holocephalans alone possess a mandibulohyoideus (interhyoideus of Didier

956 (1995), geniohyoideus of Kesteven (1933)) linking the mandible to the ceratohyal. Although 
957

958

959

960

961

962

963

964

965

966

967

968

969

970

971

972

973

974

975

976

977

978

979

980

981

morphologically similar to the geniohyoideus of osteichthyans, Anderson (2008) argues that the muscles are not homologous. Rather, the plesiomorphic means of depressing the mandible in crown-gnathostomes is broadly thought to be achieved by the coracomandibularis (Anderson, 2008; Johanson, 2003, p. 20; Wilga et al., 2000). In living holocephalans like Callorhinchus the muscle attaches to a pronounced ventral process on the broad ceratohyal. Iniopera also possesses a large, flat ceratohyal with a similar process, suggesting that this morphology was present at least in iniopterygians in the holocephalan stem-group (Pradel pers. obs.). Ozarcus, as well as stemchondrichthyans such as Acanthodes, Ptomacanthus, and Gladbachus instead have long, thin ceratohyals with no such process (Coates et al., 2018; Dearden et al., 2019; Miles, 1973; Pradel et al., 2014) bolstering the idea that such a muscle was absent in the early holocephalan and chondrichthyan stem-groups, and that its evolution is linked to a holostylic jaw suspension. However, it is difficult to rule out the possibility completely: in osteichthyans with a geniohyoideus, for example Amia (Allis, 1897; Anderson, 2008) the ceratohyal is not necessarily long and thin. If this muscle is novel in chimaeroids it may be linked to their unusual ventilatory process, which is based on fore-aft movements (Dean et al., 2012) and which may have been present some chondrichthyan stem-group members (Pradel pers. obs.).

The extended and compact pharynxes in elasmobranchs and holocephalans respectively necessitate major differences in branchial musculature. Although a sub-cranial pharynx is likely plesiomorphic for crown-group gnathostomes and is present in some stem-chondrichthyans (Dearden et al., 2019), it does seem that a posteriorly extended pharynx was present at the divergence of elasmobranchs and holocephalans, given this state in several stem-chondrichthyans and putative stemholocephalans (Coates et al., 2018; Pradel et al., 2014). Despite the major shift to a holocephalan condition, many of the muscles of the elasmobranch pharynx are preserved in Callorhinchus including hyoid and branchial constrictors, the subspinalis muscle, interpharyngobranchialis muscles and the interarcuales muscles, suggesting that these were present in the ancestral crown- 
982 chondrichthyan. Linked to this shift is the close muscular association of the neurocranium with the

983 scapulocoracoid via the cucullaris superficialis, cucullaris profundus, and protractor dorsalis

984 pectoralis. Skeletal correlates for these muscles are difficult to find, but a sub-cranial branchial

985 skeleton is present in several Paleozoic stem-holocephalans including iniopterygians and Debeerius,

986 suggesting that they may have been present (Grogan and Lund, 2000; Pradel et al., 2010). In

987 Chondrenchelys the branchial skeleton appears to be more posteriorly placed (Finarelli and Coates,

988 2014). Given this and the extended pharynxes of some stem-chondrichthyans and stem-

989 holocephalans an elasmobranch-like extended cucullaris seems likely to be plesiomorphic for

990 chondrichthyans with a separate cucullaris profundus and cucullaris superficialis muscles having

991 evolved in the holocephalan stem-group perhaps crownwards relative to Chondrenchelys.

992 A holocephalan-like hyoid operculum with its greatly enlarged hyoid constrictor muscles seems

993 likely to be derived and linked to a ventrally placed branchial skeleton. However, its

994 presence/absence can be difficult to detect in the fossil record as the evidence for gill slits/operculae

995 is often indirect. In one Upper Devonian cladoselachian specimen the muscles and branchial rays

996 are preserved, demonstrating an elasmobranch-like arrangement of both (Maisey, 1989). In several

997 other Paleozoic "sharks" posteriorly extended branchial skeletons such as Triodus and Tristychius

998 operculae have been inferred on the basis of enlarged hyoid rays, although some of these have since

999 been disputed (discussed in Coates et al., 2018, supp. mat.). An enlarged hyoid operculum is not

1000 necessarily mutually exclusive with posteriorly extending branchial arches. In several acanthodian-

1001 grade stem-chondrichthyans, where the gill slits are observable in the patterning of the dermal

1002 shagreen, both an enlarged hyoid operculum and several posterior gill slits can be observed

1003 (Watson, 1937). So, while the holocephalan sub-neurocranial pharynx is derived an enlarged

1004 operculum may run deeper into the holocephalan, or even chondrichthyan, stem-group.

\section{Conclusions}


1006 Here, we completely describe for the first time in 3D the two different chondrichthyan cranial

1007 muscle arrangements, in a model holocephalans and elasmobranch. The reduced, but recognizably

1008 shark-like branchial musculature we identify in Callorhinchus, and the likely derived origins of

1009 most holocephalan cranial musculature based on fossil evidence, do not match the idea that

1010 holocephalans display a primitive collection of archetypal chondrichthyan conditions. Instead, they

1011 fit into an emerging picture where holocephalan anatomy comprises a set of apomorphic conditions

1012 with their origins in a shark-like form (Coates et al. 2018). Parts of this holocephalan anatomical

1013 suite, such as the unique hyoid arch morphology and mandibulohyoideus, may be functionally

1014 linked to their novel mode of respiration (Dean et al. 2012). A shark-like cranial musculature, with

1015 an extended pharynx and a postorbital and ethmoid jaw suspension, seems the likely ancestral state

1016 at the chondrichthyan crown-node. Digital dissections provide a unique way of describing and

1017 sharing anatomical structures in 3D and can help identify muscles which are difficult to view in

1018 gross dissection. However, this should be seen as a complement, rather than a substitute, to

1019 traditional methods as the resolution of scan data and the inability to manipulate and examine

1020 tissues directly create limitations on what can be seen. We hope this data will, alongside digital

1021 dissections from a broad array of organisms, help others to make better inferences on the origin and 1022 evolution of the vertebrate head. 


\section{Acknowledgments}

1024 We thank the ID-19 beamline at the European Synchrotron Radiation Facility for assistance with

1025 scanning. Assistance in getting fresh Scyliorhinus canicula specimens from Didier Casane and

1026 Véronique Borday-Birraux from the Laboratoire Evolution Génomes Comportement Ecologie -

1027 CNRS, and Patrick Laurenti (Laboratoire Interdisciplinaire des Energies de Demain; Université

1028 Paris-Diderot) is gratefully acknowledged. We thank Florent Goussard (CR2P - MNHN) for his

1029 inestimable help in 3D work. Some of this work began at the AMNH with the help of John Maisey.

1030 Author contributions

1031 RPD, AH, and AP conceived and designed the study. PT and AP scanned the specimens. RPD, RM,

1032 AC, and AP processed the scan data. RPD analysed the data, with input from AP, AH, and DD. RPD

1033 wrote the paper and made figures. All authors read and provided feedback on the manuscript.

\section{Funding Statement}

1035 The main work was supported by the Paris Ile-de-France Region - DIM "Matériaux anciens et

1036 patrimoniaux"- DIM PHARE projet, the ESRF (beamline ID19, proposal ec361) and the H.R. \& E.

1037 Axelrod Research Chair in paleoichthyology at the AMNH. 
bioRxiv preprint doi: https://doi.org/10.1101/2020.07.30.227132; this version posted July 31, 2020. The copyright holder for this preprint (which

was not certified by peer review) is the author/funder, who has granted bioRxiv a license to display the preprint in perpetuity. It is made available under aCC-BY-NC-ND 4.0 International license.

\section{Data Availability Statement}

1040 All 3D data is openly available in a public repository that issues datasets with DOIs (on

1041 publication). Tomographic data is available on request from the authors. 


\section{References}

1043 Allis, E.P., 1917. The Homologies of the Muscles related to the Visceral Arches of the

1044 Gnathostome Fishes. Q. J. Microsc. Sci. 62, 303-406.

1045 Allis, E.P., 1897. The cranial muscles of Amia. J. Morphol. XII.

1046 Anderson, P.S.L., 2008. Cranial muscle homology across modern gnathostomes. Biol. J. Linn. Soc.

$104794,195-216$.

1048 Brazeau, M.D., de Winter, V., 2015. The hyoid arch and braincase anatomy of Acanthodes support

1049 chondrichthyan affinity of ‘acanthodians'. Proc. R. Soc. B Biol. Sci. 282.

1050 Brocklehurst, R., Porro, L., Herrel, A., Adriaens, D., Rayfield, E.J., 2019. A digital dissection of

1051 two teleost fishes: comparative functional anatomy of the cranial musculoskeletal system in

1052 pike (Esox lucius) and eel (Anguilla anguilla). J. Anat. 235, 189-204.

1053 https://doi.org/10.1111/joa.13007

1054 Camp, A.L., Scott, B.R., Brainerd, E.L., Wilga, C.D., 2017. Dual function of the pectoral girdle for

1055 feeding and locomotion in white-spotted bamboo sharks. Proc. R. Soc. B Biol. Sci. 284.

1056 Coates, M.I., Finarelli, J.A., Sansom, I.J., Andreev, P.S., Criswell, K.E., Tietjen, K., Rivers, M.L.,

1057 Riviere, P.J.L., Coates, M.I., 2018. An early chondrichthyan and the evolutionary assembly

1058 of a shark body plan. Proc. R. Soc. B Biol. Sci. 285.

1059 Coates, M.I., Gess, R.W., Finarelli, J.A., Criswell, K.E., Tietjen, K., 2017. A symmoriiform

1060 chondrichthyan braincase and the origin of chimaeroid fishes. Nature 541, 1-16.

$1061 \quad$ https://doi.org/10.1038/nature20806

1062 Coates, M.I., Sequeira, S.E.K., 2001. A new stethacanthid chondrichthyan from the lower

1063 Carboniferous of Bearsden, Scotland. J. Vertebr. Paleontol. 21, 438-459.

1064 https://doi.org/10.1671/0272-4634

1065 Coates, M.I., Tietjen, K., Olsen, A.M., Finarelli, J.A., 2019. High-performance suction feeding in

1066 an early elasmobranch. Sci. Adv. 5. https://doi.org/10.1126/sciadv.aax2742 
1067 Coolen, M., et al. 2008. The dogfish Scyliorhinus canicula: A reference in jawed vertebrates. Cold

1068 Spring Harb. Protoc. 3. https://doi.org/10.1101/pdb.emo111

1069 Cox, P.G., Faulkes, C.G., 2014. Digital dissection of the masticatory muscles of the naked mole-rat,

1070 Heterocephalus glaber (Mammalia, Rodentia). PeerJ 2014, 1-19.

1071 https://doi.org/10.7717/peerj.448

1072 de Beer, G.R., 1931. The Development of the Skull of Scyllium (Scyliorhinus) canicula L. Q. J.

1073 Microsc. Sci. 74, 591-652.

1074 De Beer, G.R., Moy-Thomas, J.A., 1935. On the Skull of Holocephali. Philos. Trans. R. Soc. Lond.

1075 B. Biol. Sci. 224, 287-312.

1076

Dean, M.N., Summers, A.P., Ferry, L.A., 2012. Very low pressures drive ventilatory flow in chimaeroid fishes. J. Morphol. 273, 461-479. https://doi.org/10.1002/jmor.11035

1078

Dearden, R.P., Stockey, C., Brazeau, M.D., 2019. The pharynx of the stem-chondrichthyan Ptomacanthus and the early evolution of the gnathostome gill skeleton. Nat. Commun. 10, 1-7. https://doi.org/10.1038/s41467-019-10032-3

Dearden, R.P. et al. 2020. Supplementary information for "The pharynx of the stem-chondrichthyan Ptomacanthus and the early evolution of the gnathostome gill skeleton." 3D pdfs, Figshare. https://doi.org/10.6084/m9.figshare.12727337

1084 Available at: https://figshare.com/s/1e16cd81293498b970b5

Dearden, R.P. et al. 2020. Supplementary information for "The pharynx of the stem-chondrichthyan Ptomacanthus and the early evolution of the gnathostome gill skeleton." Callorhinchus milii 3D files, Figshare. https://doi.org/10.6084/m9.figshare.12727121 Available at: https://figshare.com/s/6e5b73cc5b65790f2a33 
1093

1094

1095

1096

1097

1098

1099

1100

1101

1102

1103

1104

1105

1106

1107

1108

1109

1110

1111

1112

1113

1114

1115

1116

Denton, J.S.S., et al., 2018. Cranial morphology in Mollisquama sp. (Squaliformes; Dalatiidae) and patterns of cranial evolution in dalatiid sharks. J. Anat. 233, 15-32. https://doi.org/10.1111/joa.12823

Didier, D.A., 1995. Phylogenetic Systematics of Extant Chimaeroid Fishes (Holocephali, Chimaeroidei). Am. Mus. Novit.

Didier, D.A., Leclair, E.E., Vanbuskirk, D.R., 1998. Embryonic Staging and External Features of Development of the Chimaeroid Fish, Callorhinchus milii (Holocephali, Callorhinchidae). J. Morphol. 47, 25-47.

Edgeworth, F.H., 1935. The cranial muscles of vertebrates. Cambridge University Press, London, UK.

Edgeworth, F.H., 1902. The Development of the Head Muscles in Scyllium Canicula. J. Anat. Physiol. 37, 73-88.

Finarelli, J.A., Coates, M.I., 2014. Chondrenchelys problematica (Traquair, 1888) redescribed: a Lower Carboniferous, eel-like holocephalan from Scotland. Earth Environ. Sci. Trans. R. Soc. Edinb. 105, 35-59. https://doi.org/10.1017/S1755691014000139

Grogan, E.D., Lund, R., 2000. Debeerius ellefseni (Fam. Nov., Gen. Nov ., Spec. Nov.), an Autodiastylic Chondrichthyan From the Mississippian Bear Gulch Limestone of Montana (USA), the Relationships of the Chondrichthyes, and Comments on Gnathostome Evolution. J. Morphol. 245, 219-245.

Grogan, E.D., Lund, R., Didier, D.A., 1999. Description of the Chimaerid Jaw and Its Phylogenetic Origins. J. Morphol. 59, 45-59.

Holmgren, N., 1940. Development of the Skull in Sharks and Rays. Acta Zool. 21.

Hughes, G.M., Ballintijn, C.M., 1965. The Muscular Basis of the Respiratory Pumps in the Dogfish (Scyliorhinus Canicula). J. Exp. Biol. 43, 363-383. 
1117 Inoue, J.G. et al., 2010. Evolutionary origin and phylogeny of the modern holocephalans

1118 (Chondrichthyes: Chimaeriformes): a mitogenomic perspective. Mol. Biol. Evol. 27, 2576-

1119 86. https://doi.org/10.1093/molbev/msq147

1120 Johanson, Z., 2003. Placoderm branchial and hypobranchial muscles and origins in jawed

1121 vertebrates. J. Vertebr. Paleontol. 23, 735-749. https://doi.org/10.1671/2

1122 Kesteven, H.L., 1933. The anatomy of the head in Callorhynchus antarcticus. J. Anat. 67, 443-474.

1123 Klinkhamer, A.J., Wilhite, D.R., White, M.A., Wroe, S., 2017. Digital dissection and three-

1124 dimensional interactive models of limb musculature in the Australian estuarine crocodile

1125 (Crocodylus porosus). PLoS ONE 12, 17-22. https://doi.org/10.1371/journal.pone.0175079

1126 Lauder, G.V., 1980. On the evolution of the jaw adductor musculature in primitive gnathostome

1127 fishes. Breviora.

1128 Lautenschlager, S., Bright, J.A., Rayfield, E.J., 2014. Digital dissection - using contrast-enhanced

1129 computed tomography scanning to elucidate hard- and soft-tissue anatomy in the Common

1130 Buzzard, Buteo buteo. J. Anat. 224, 412-431. https://doi.org/10.1111/joa.12153

1131 Licht, M., Schmuecker, K., Huelsken, T., Hanel, R., Bartsch, P., Paeckert, M., 2012. Contribution

1132 to the molecular phylogenetic analysis of extant holocephalan fishes (holocephali,

1133 chimaeriformes). Org. Divers. Evol. 12, 421-432. https://doi.org/10.1007/s13127-011-0071-

$1134-1$

1135 Luther, A.F., 1909a. Beitrage zur Kenntnisse von Muskulatur und Skelett des Kopfes des Haies

1136 Stegostoma tigrinum Gm. und der Holocephalen mit einem Anhamg ueber die Nasenrinne

1137 Author(s): Acta Soc. Sci. Fenn. 37, 1-50. https://doi.org/10.1007/BF03017512

1138 Luther, A.F., 1909b. Untersuchungen uber die von N. trigeminus innervierte Musculator der

1139 Selachier (Haie und Rochen) unter Berucksichtigung ihrer Beziehungen zu benachbarten

$1140 \quad$ Organen. Acta Soc Sci Fenn 36, 1-176.

1141 Maisey, J.G., 2008. The postorbital palatoquadrate articulation in elasmobranchs. J. Morphol. 269,

1142 1022-1040. https://doi.org/10.1002/jmor.10642 
1143 Maisey, J.G., 2007. The Braincase in Paleozoic Symmoriiform and Cladoselachian Sharks. Bull.

1144 Am. Mus. Nat. Hist. 307, 1-122.

1145 Maisey, J.G., 2001. A primitive chondrichthyan braincase from the Middle Devonian of Bolivia, in:

1146 Ahlberg, P.E. (Ed.), Major Events in Early Vertebrate Evolution. Taylor and Francis,

1147 London, UK, pp. 263-288.

1148 Maisey, J.G., 1989. Visceral skeleton and musculature of a Late Devonian shark. J. Vertebr.

1149 Paleontol. 9, 174-190. https://doi.org/10.1080/02724634.1989.10011751

1150 Maisey, J.G., 1984. Chondrichthyan phylogeny: a look at the evidence. J. Vertebr. Paleontol. 4,

1151 359-371. https://doi.org/10.1080/02724634.1984.10012015

1152 Maisey, J.G., 1980. An Evaluation of Jaw Suspension in Sharks. Am. Mus. Novit. 1-17.

1153 Maisey, J.G., Miller, R.F., Turner, S., 2009. The braincase of the chondrichthyan Doliodus from the

1154 Lower Devonian Campbellton Formation of New Brunswick, Canada. Acta Zool. 90, 109-

1155 122. https://doi.org/10.1111/j.1463-6395.2008.00330.x

1156 Miles, R.S., 1973. Relationships of acanthodians, in: Greenwood, P., Miles, R.S., Patterson, C.

1157 (Eds.), Interrelationships of Fishes. London: Zoological Journal of the Linnean Society, pp.

$1158 \quad 63-103$.

1159 Nakaya, K., 1975. Taxonomy, comparative anatomy, and phylogeny of Japanese catsharks,

1160 Scyliorhinidae. Mem. Fac. Fish. Hokkaido Univ. 23, 1-94.

1161 Nelson, J.S., Grande, T.C., Wilson, M.V.H., 2016. Fishes of the World. Wiley.

1162 Oulion, S., Borday-Birraux, V., Debiais-Thibaud, M., Mazan, S., Laurenti, P., Casane, D., 2011.

1163 Evolution of repeated structures along the body axis of jawed vertebrates, insights from the

1164 Scyliorhinus canicula Hox code: Evolution of repeated structures, insights from the S.

1165 canicula Hox code. Evol. Dev. 13, 247-259. https://doi.org/10.1111/j.1525-

$1166 \quad$ 142X.2011.00477.x

1167 Patterson, C., 1965. The phylogeny of the chimaeroids. Philos. Trans. R. Soc. Lond. B. Biol. Sci.

$1168 \quad 249,101-219$. 
1169 Porro, L.B., Richards, C.T., 2017. Digital dissection of the model organism Xenopus laevis using contrast-enhanced computed tomography. J. Anat. 231, 169-191. https://doi.org/10.1111/joa.12625

1172 Pradel, A., 2010. Skull and brain anatomy of Late Carboniferous Sibyrhynchidae Skull and brain anatomy of Late Carboniferous Sibyrhynchidae (Chondrichthyes, Iniopterygia) from Kansas and Oklahoma (USA). Geodiversitas 32, 595-661.

Pradel, A., Didier, D.A., Casane, D., Tafforeau, P., Maisey, J.G., 2013. Holocephalan Embryo Provides New Information on the Evolution of the Glossopharyngeal Nerve, Metotic Fissure and Parachordal Plate in Gnathostomes. PLoS ONE 8, e66988.

Pradel, A., Langer, M., Maisey, J.G., Geffard-Kuriyama, D., Cloetens, P., Janvier, P., Tafforeau, P., 2009. Skull and brain of a 300-million-year-old chimaeroid fish revealed by synchrotron holotomography. Proc. Natl. Acad. Sci. U. S. A. 106, 5224-5228.

Pradel, A., Maisey, J.G., Tafforeau, P., Mapes, R.H., Mallatt, J., 2014. A Palaeozoic shark with

1184

1185

1186 osteichthyan-like branchial arches. Nature 509, 608-11. https://doi.org/10.1038/nature13195

Pradel, A., Tafforeau, P., Janvier, P., 2010. Study of the pectoral girdle and fins of the Late Carboniferous sibyrhynchid iniopterygians (Vertebrata, Chondrichthyes, Iniopterygia) from Kansas and Oklahoma (USA) by means of microtomography, with comments on iniopterygian relationships. Comptes Rendus Palevol 9, 377-387. https://doi.org/10.1016/j.crpv.2010.07.015

Raikow, R.J., Swierczewski, E.V., 1975. Functional anatomy and sexual dimorphism of the cephalic clasper in the pacific ratfish (Chimaera collei). J. Morphol. 145, 435-439. https://doi.org/10.1002/jmor.1051450404

Ramsay, J.B., et al., 2015. Eating with a saw for a jaw: Functional morphology of the jaws and tooth-whorl in Helicoprion davisii. J. Morphol. 276, 47-64. https://doi.org/10.1002/jmor.20319 
1195 Reif, W.E., 1980. Development of Dentition and Dermal Skeleton in Embryonic Scyliorhinus canicula’'288, 275-288.

1197 Ridewood, W.G., 1899. On the eyelid-muscles of the carchariidae and Scyllium: a contribution to 1198 the morphology of the nictitating membrane of sharks. J. Anat. Physiol. 33, 228-242.

1199 Shann, E.W., 1919. The comparative myology of the shoulder girle and pectoral fin of fishes.

$1200 \quad$ Trans. R. Soc. Edinb. 52.

1201 Sharp, A.C., Trusler, P.W., 2015. Morphology of the jaw-closing musculature in the common

1202 wombat (Vombatus ursinus) using digital dissection and magnetic resonance imaging. PLoS ONE 10, 1-19. https://doi.org/10.1371/journal.pone.0117730

1205

Soares, M.C., Carvalho, M.R.D., 2013. Mandibular and Hyoid Muscles of Galeomorph Sharks (Chondrichthyes $\square$ : Elasmobranchii), with Remarks on Their Phylogenetic Intrarelationships. J. Morphol. https://doi.org/10.1002/jmor.20166

Tomita, T., Toda, M., Miyamoto, K., Ueda, K., Nakaya, K., 2018. Morphology of a Hidden Tube: Resin Injection and CT Scanning Reveal the Three-dimensional Structure of the Spiracle in the Japanese Bullhead Shark Heterodontus japonicus (Chondrichthyes; Heterodontiformes;

Vetter, B., 1878. Untersuchungen zur vergleichenden Anatomie der Kiemen- und Kiefermuskeln der Fische. II Teil. Jena Z Naturwiss 12, 431-550. 146. https://doi.org/10.2307/1436828

Wilga, C.D., 2005. Morphology and evolution of the jaw suspension in lamniform sharks. J.

1217 Wilga, C.D., Wainwright, P.C., Motta, P.J., 2000. Evolution of jaw depression mechanics in aquatic vertebrates: Insights from chondrichthyes. Biol. J. Linn. Soc. 71, 165-185.

1219 https://doi.org/10.1006/bij1.1999.0436 
1220 Zangerl, R., 1966. A new shark of the family Edestidae, Ornithoprion hertwigi, from the

1221 Pennsylvanian Mecca and Logan quarry shales of Indiana. Fieldiana 16, 1-43.

1222 Ziermann, J.M., Miyashita, T., Diogo, R., 2014. Cephalic muscles of Cyclostomes (hagfishes and

1223 lampreys) and Chondrichthyes (sharks, rays and holocephalans): comparative anatomy and

1224 early evolution of the vertebrate head muscles. Zool. J. Linn. Soc. 172, 771-802.

1225 https://doi.org/10.1111/zoj.12186 
bioRxiv preprint doi: https://doi.org/10.1101/2020.07.30.227132; this version posted July 31, 2020. The copyright holder for this preprint (which

was not certified by peer review) is the author/funder, who has granted bioRxiv a license to display the preprint in perpetuity. It is made available under aCC-BY-NC-ND 4.0 International license.

\section{Supporting Information}

1227 The datasets supporting this work are available at the private figshare links below. Included are 3D

1228 pdfs and plys of all models.

1229 SI1: 3D pdfs, https://figshare.com/s/1e16cd81293498b970b5

1230 SI2: Callorhinchus 3D models, (plys): https://figshare.com/s/6e5b73cc5b65790f2a33

1231 SI3: Scyliorhinus 3D models, (plys): https://figshare.com/s/815ceadc2a356d9ec79d 


\section{Figure Captions}

1233 Figure 1. The neurocranium of Callorhinchus milii in (a) lateral, (b) anterior, (c) dorsal, (d)

1234 posterior, and (e) ventral views. Abbreviations: antorb. proc., antorbital process; dors. proc. dorsal

1235 process; eff. pseud., foramen for the efferent pseudobranchial artery; endo. duct, foramen for

1236 endolymphatic duct; eth. can. Ant, anterior ethmoid canal foramina eth. can. oph, entry into

1237 ethmoid canal for superficial ophthalmic complex; eth. can. prof, entry into ethmoid canal for

1238 profundus nerve; eth. can. tw., exit from ethmoid canal for twigs of the superficial ophthalmic

1239 complex/profundus; eth. proc., ethmoid process; for. mag.; foramen magnum; for. br. nas.,

1240 foraminae for branches of the nasal vein; gloss for. (IX), foramen for glossopharyngeal (IX) nerve;

1241 hyo. fac. (VII), foramen for hyomandibular branch of the facial (VII) nerve; hyomand.,

1242 hyomandibula; hyp. groove., hypophyseal groove; 1. rost. rod, lateral rostral rod; ?lig. pharh.,

1243 ?ligamentum pharyngohyoideus; $\mathrm{m}$. rost. rod, median rostral rod; nas. vein gr., groove for the nasal

1244 vein; noto. for., notochord foramen; occ. crest, occipital crest; occ. cot., occipital cotylus; olf. cap.,

1245 olfactory capsules; orbnas. can., foramen for the orbitonasal canal; pal. fac. (VII), foramen for

1246 palatine branch of the facial (VII) nerve; ped. foss., fossa for pedicular cartilage; pharh,

1247 pharyngohyal; postorb. ridge, postorbital ridge; quad. proc., quadrate process; spin. nerves,

1248 foraminae for anterior spinal nerves; suborb. shelf, suborbital shelf; supraorb. shelf, supraorbital

1249 shelf; unchond. area, incompletely chondrified area; vagus for. (X), foramen for vagus (X) nerve

1250 Figure 2. The cranial skeleton of Callorhinchus milii (a) complete skeleton in lateral view, (b)

1251 antero-lateral view showing labial cartilages, (c) ventral pharyngeal skeleton in dorsal view, (d)

1252 dorsal pharyngeal skeleton in ventral view, lower jaw in ventral (e) and dorsal (f) view, and (g)

1253 palate in ventral view. Colours: cream, cartilage; beige, sphenoptic membrane; red, ligaments.

1254 Abbreviations: add. ang., adductor mandibulae angle; bbr., basibranchials; basih., basihyal; cbr.,

1255 ceratobranchial; ceratoh, ceratohyal; chin pr., chin process; cop., basibranchial copula; ebr, 
1256 epibranchial; hyomand., hyomandibula; hbr., hypobranchial; imax., inferior maxillary cartilage; lat.

1257 foss., lateral fossa of Meckel's cartilage; lat. proc., lateral process of quadrate; lig. lab., ligamentum

1258 labialis; lig. rost., ligamentum rostralis; mand. tp., mandibular toothplates; Meck., Meckel's

1259 cartilage; oper., opercular cartilage; med. foss, medial fossa of quadrate; med. proc., medial process

1260 of Meckel's cartilage; pal. tp. palatine toothplates; ped. pedicular cartilage; pharh, pharyngohyal;

1261 plab., prelabial cartilage; pmand. premandibular cartilage; pbr., pharyngobranchial; pmax.,

1262 premaxillary cartilage; post. comp., posterior epibranchial/pharyngobranchial complex; smax.,

1263 superior maxillary cartilage; unchond. emb., unchondrified embayment; vom. tp., vomerine

1264 toothplates

1265 Figure 3. The orbit of Callorhinchus milii shown in lateral view with skeleton in (a) lateral and (b)

1266 antero-lateral view and (c)lateral view with external optic muscles and cranial nerves. Colours as in

1267 Fig. 3 with light-blue for cranial nerves. Abbreviations: fac. (VII), facial (VII) nerve; hyo. fac.

1268 (VII), foramen for hyomandibular branch of the facial (VII) nerve; m. obl. dors., m. obliquus

1269 dorsalis; m. obl. vent., m. obliquus ventralis; $m$. rect. dors., m. rectus dorsalis; m. rect. lat., m.

1270 rectus lateralis; $m$. rect. med., m. rectus medialis; m. rect. vent., m. rectus ventralis; oph. for.

1271 ophthalmic foramen; opt. (II), optic nerve; opt. (II) op., optic nerve opening; orbnas. can., foramen

1272 for the orbitonasal canal; pal. fac. (VII), foramen for palatine branch of the facial (VII) nerve; prof.

1273 for., foramen for profundus; prof. (V), profundus (V) nerve; ret. art., retinal artery opening; sup.

1274 oph. (V), superficial ophthalmic complex (V+anterodorsal lateral line nerves); sup. oph. for.,

1275 foramen for superficial ophthalmic complex's entry into orbit; for. V+VII, foramen for entry of

1276 trigeminal (V) and facial (VII) nerves into the orbit.

1277 Figure 4. Lateral view of the head of Callorhinchus milii with progressively shallower muscles

1278 shown. Colours: cream, cartilage; beige, sphenoptic membrane; red, ligaments; pinks, muscles;

1279 greys, deeper muscles. Abbreviations: mm. add. arc. br., mm. adductors arcuum branchiales; $m$. 
1280 add. mand. ant., m. adductor mandibulae anterior; m. add. mand. post., m. adductor mandibulae

1281 posterior; mm. con. branchiales, mm. constrictors branchiales; m. con. oper. dors,. m. constrictor

1282 opercula dorsalis; m. con. oper. dors. ant., m. constrictor operculi dorsalis anterior; m. con. oper.

1283 vent., m. constrictor operculi ventralis; m. coracohy., mm. coracohyoideus; mm. coracobr., mm.

1284 coracobranchiales; m. coracoma., m. coracomandibularis (coloured in two shades to show

1285 division); m. cuc. prof., m. cucullaris profundus; m. cuc. sup., m. cucullaris superficialis; mm. int.

1286 br., m. interarcuales branchiales; m. intermand., m. intermandibularis; $m$. lab. ant., m. labialis

1287 anterior; m. lev. ang. oris ant., m. levator anguli oris anterior; m. lev. ang. oris ant. pars. rost., m.

1288 levator anguli oris anterior pars rostralis; $m$. lev. ang. oris post., levator anguli oris posterior; $m$.

1289 lev. hyoid., m. levator hyoideus; m. mandibulohy., m. mandibulohyoideus; m. prot. dors. pect., m.

1290 protractor dorsalis pectoralis; m. ret. dors. pect., m. retractor dorsalis pectoralis; m. ret. lat.-vent.

1291 pect. l, m. retractor latero-ventralis pectoralis lateral; m. ret. lat.-vent. pect. m, m. retractor latero-

1292 ventralis pectoralis medial; m. ret. mes.-vent. pect., m. retractor mesio-ventralis pectoralis; $m$.

1293 subspin, m. subspinalis; m. superfic., m. superficialis

1294 Figure 5. Ventral view of the head of Callorhinchus milii with (a) deepest muscles, (b) deeper

1295 muscles, and (c) shallow muscles overlain. Colours and abbreviations as in Fig. 4.

1296 Figure 6. Branchial skeleton of Callorhinchus milii with (a) in postero-lateral view with semi-

1297 transparent neurocranium and scapulocoracoid, (b) in medial view, and (c) in antero-medial view

1298 with a semi-transparent mandible. Colours and abbreviations as in Fig. 3. Additional abbreviations:

1299 m. con. oes., m. constrictor oesophagi; m. coracoma. r. arm, right "arm" of m. coracomandibularis

1300 (left not pictured); m. interphar; m. interpharyngobranchialis. Otherwise as for Fig. 4.

1301 Figure 7. The neurocranium of Scyliorhinus canicula in (a) ventral, (b) dorsal, (c) lateral, (d)

1302 anterior, and (e) posterior views. Abbreviations: ant. Lor., anterior depression for ampullae of 
1303 Lorenzini; endo. duct, endolymphatic duct; endo. fossa, endolymphatic fossa; for. mag., foramen

1304 magnum; gloss. (IX) can., glossopharyngeal (IX) nerve canal exit; hyomand. art, hyomandibular

1305 articulation surface.; int. car. for., foramen for the internal carotids; intn. pl., internasal plate; jug.

1306 groove, jugular groove; lat. Lor., lateral furrows for ampullae of Lorenzini; postorb. can. for.,

1307 foramen for postorbital sensory canal; occ. cond., occipital condyle; occ. cot., occipital cotylus; occ.

1308 proc., occipital processes; orb. art., foramen for the orbital artery; peri. duct, perilymphatic duct;

1309 postorb. can. for., foramen for postorbital sensory canal; postorb. proc., postorbital process; pre.

1310 font., precerebral fontanelle; rost. rod 1, lateral rostral rod; rost. rod m., median rostral rod; scr. cart.,

1311 scrolled cartilage; suborb. shelf ;supoph. for. foraminae for twigs of the superophthalmic complex;

1312 supoph. for., foraminae $\mathrm{n}$ for the superophthalmic complex; supoph. for. ant., anterior foramen for

1313 the superophthalmic complex; suporb. ridge, supraorbital ridge; unchond., incompletely chondrified

1314 area; vagus $(\mathrm{X})$ can., vagus $(\mathrm{X})$ nerve canal exit

1315 Figure 8. Cranial skeleton of Scyliorhinus canicula with (a) whole cranial skeleton in lateral view,

1316 mandibles in (b) lateral and (c) medial view, (d) left Meckel's cartilage in dorsal view, (e) left

1317 palatoquadrate in ventral view, (f) dorsal gill skeleton in ventral view and ( $\mathrm{g}$ ) ventral gill skeleton in

1318 dorsal view. Abbreviations: basih., basihyal; br. ray; branchial rays; ceratoh, ceratohyal; cbr.,

1319 ceratobranchial; cop., basibranchial copula; dent. sulc., dental sulcus; lab. d., dorsal labial cartilage;

1320 eth. proc., ethmoid process; ebr, epibranchial; exbr. d., dorsal extrabranchial cartilages; exbr. v.,

1321 ventral extrabranchial cartilages; hyomand., hyomandibula; hyo. ray, hyoid rays; hbr.,

1322 hypobranchial; lab. v., ventral labial cartilage; lat. foss., lateral fossa of Meckel's cartilage; lat.

1323 proc., lateral process of palatoquadrate; Meck., Meckel's cartilage; med. foss, medial fossa of

1324 palatoquadrate; med. proc., medial process of Meckel's cartilage; palatoq., palatoquadrate; pbr.,

1325 pharyngobranchial; post. comp., posterior epibranchial/pharyngobranchial complex 
1326 Figure 9. The orbit of Scyliorhinus canicula shown in lateral view with (a) foraminae shown, and

1327 (b) external optic muscles and cranial nerves. Colours as in Fig. 9 with light-blue for cranial nerves.

1328 Abbreviations: abd (IV) for., foramen for the abducens (IV) nerve; ant. cer. v., foramen for the

1329 anterior cerebral vein; eff. pseud, foramen for the efferent pseudobranchial artery; m. obl. dors., $m$.

1330 obliquus dorsalis; m. obl. vent., m. obliquus ventralis; m. rect. dors., m. rectus dorsalis; m. rect.

1331 lat., m. rectus lateralis; m. rect. med., m. rectus medialis; m. rect. vent., m. rectus ventralis; oculom.

1332 (III) for., foramen for the oculomotor (III) nerve; opt (II), optic nerve; orbnas. can., foramen for the

1333 orbitonasal canal; opt. (II) for., foramen for the optic (II) nerve; orb. art., foramen for the orbital

1334 artery; pit. v., foramen for pituitary vein; prof. for., foramen for profundus; supoph. for. ant.,

1335 anterior foramen for the superophthalmic complex; sup. oph., superficial ophthalmic complex (V);

1336 supoph. for. post., posterior foramen for the superophthalmic complex; V+VII, foramen for entry of

1337 trigeminal (V) and facial (VII) nerves into the orbit; trig. (V), trigeminal nerve

1338 Figure 10. Lateral view of the head of Scyliorhinus canicula with (a-c) progressively shallower

1339 muscles shown. Colours: cream, cartilage; beige, pinks, muscles; greys, deeper muscles.

1340 Abbreviations: mm. add. branch., m. adductors branchiales; m. add. mand., m. adductor

1341 mandibulae; mm. arc. dors., mm. arcuales branchiales; m. con. hy. dors. m. constrictor hyoideus

1342 dorsalis; m. con. hy. vent. m. constrictor hyoideus ventralis; mm. con. sup., mm. constrictors

1343 superficiales; $m$. coracoarc., m. coracoarcualis; mm. coracobr., mm. coracobranchiales; $m$.

1344 coracohy., m. coracohyoideus; m. coracoma., m. coracomandibularis; m. cuc. prof., m. cucullaris

1345 profundus; m. epax., m. epaxialis; mm. interphar., mm. interpharyngobranchiales; m. intermand.,

1346 m. intermandibularis; m. lev. lab. sup., m. levator labii superioris; m. lev. pal., m. levator

1347 palatoquadrate; m. lev. palp. nict., m. levator palpebrae nictitantis; m. subspin., m. subspinalis; m.

1348 ret.palp. sup., m. retractor palpebrae superioris

1349 Figure 11. Ventral view of the head of Scyliorhinus canicula with (a) deepest muscles, (b) deeper 
bioRxiv preprint doi: https://doi.org/10.1101/2020.07.30.227132; this version posted July 31, 2020. The copyright holder for this preprint (which

was not certified by peer review) is the author/funder, who has granted bioRxiv a license to display the preprint in perpetuity. It is made available under aCC-BY-NC-ND 4.0 International license.

1350 muscles, and (c) shallow muscles overlain. Colours and abbreviations as in Fig. 10.

1351 Figure 12. Branchial skeleton of Scyliorhinus canicula (a) in dorsal view, with neurocranium (b) in

1352 dorsal view with neurocranium removed and dorsal branchial skeleton semi-transparent, and (c) in

1353 medial view with nerocranium and central gill-skeleton semi-transparent. Colours and abbreviations

1354 as in Fig. 10. 


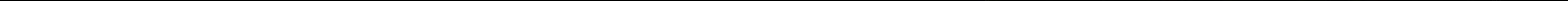


(a) sup. oph. for. (b) sup. oph. for.

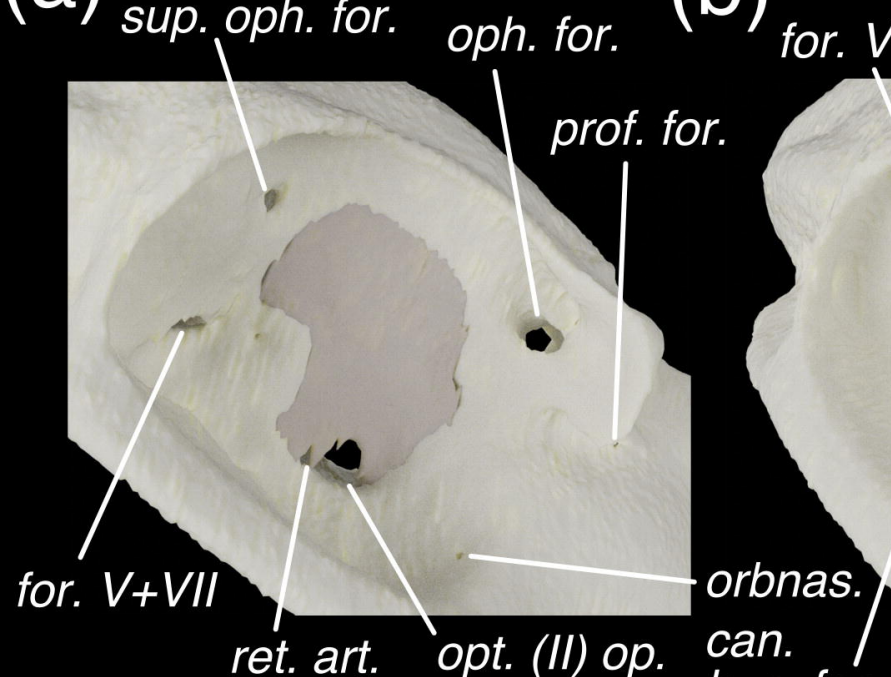

$5 \mathrm{~mm}$ ret. art. opt. (II) op.
(C)m. rect. m. rect. sup. oph. (V) lat. dors. 1 m. obl. ldors.

m. rect.

med.

$\checkmark$

m. rect.

vent.

pal. fac. (VII)

fac. (VII). prof. (V). m. obl. ret. art. opt. (II) op. opt. (II) vent. 
(b) m. ret. m. subspin.

m. add (Dors. pect.

mand. post. $m$. ret.

lat.-vent. pect. $m$.

- m. add.

$\mathrm{mm}$. add.

arc. br.

m. coracoma.

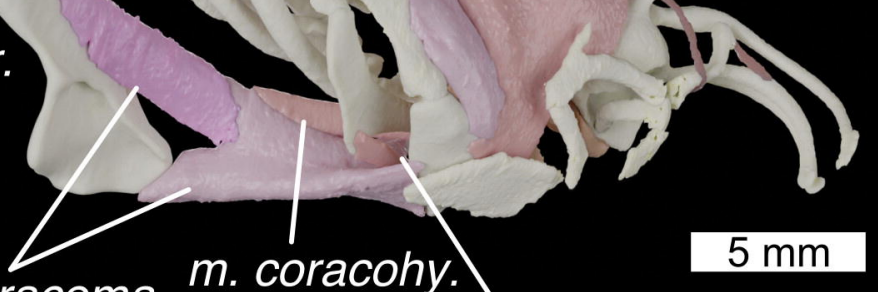

m. coracohy.

(c)

m. ret.

lat.-vent.

m. mandibulohy.

mand. ant.

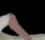

$5 \mathrm{~mm}$

m. cuc. prof.

/pect. I.
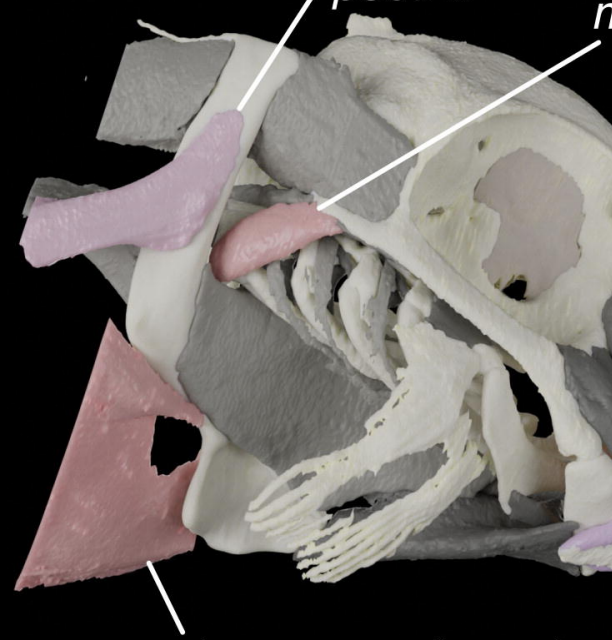

m. ret. mes.-vent. pect.

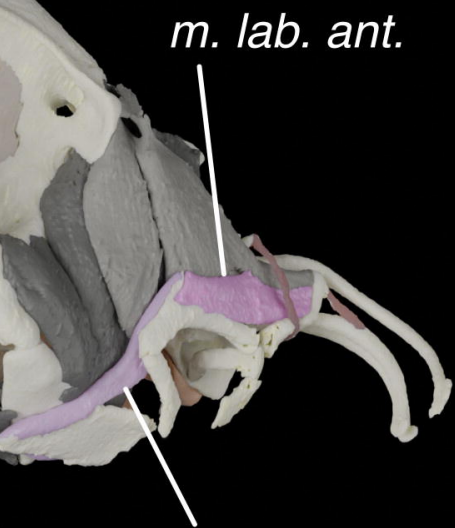

m. intermand. (d)
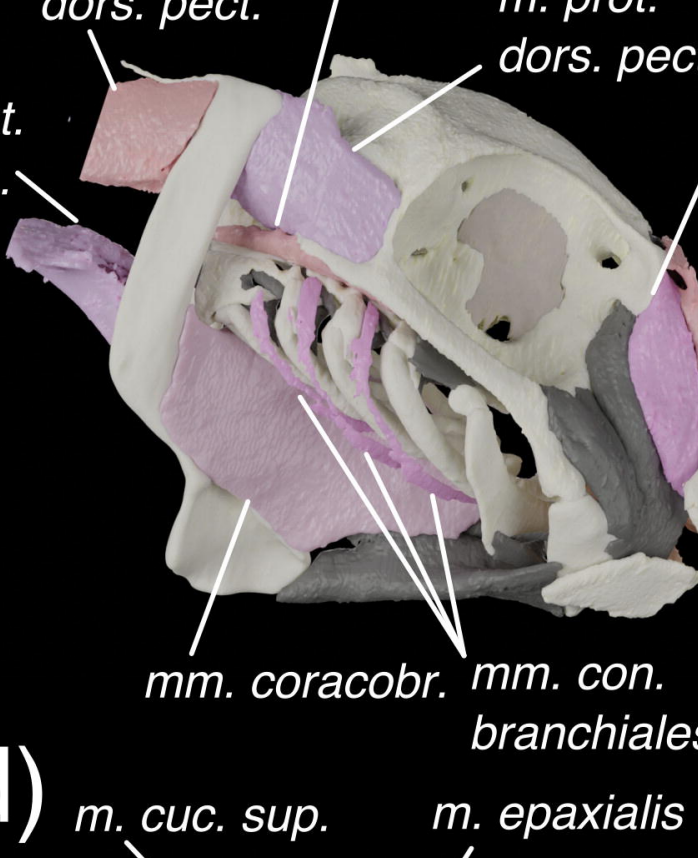

m. prot.

m. lev. ang.

oris. post.

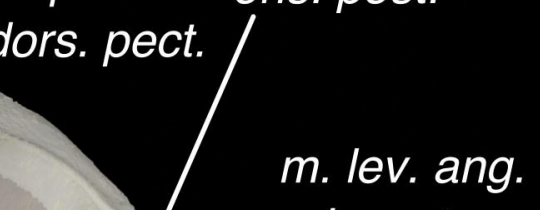
oris. ant.

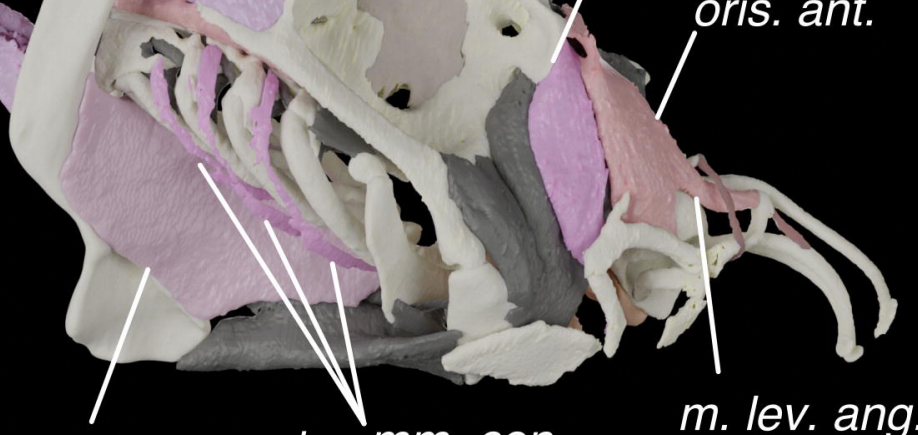

$\mathrm{mm}$. coracobr. mm. con. branchiales m. lev. ang. oris. ant. pars. rost.

m. epaxialis

m. con. oper. dors. ant.

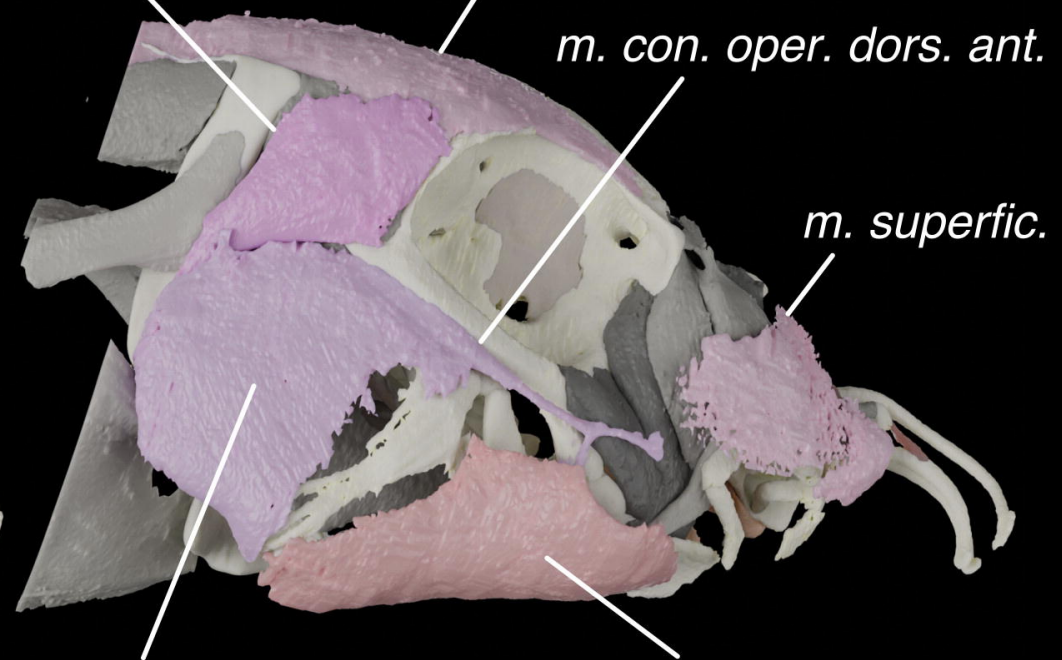

m. con. oper. vent. 

(a) intn. pl.

scr. cart.

int. car. for.

suborb. shelf

orb. art.

postorb.

can. for.

(C) occ. cond. suporb. ridge

rost. rod $\mathrm{m}$.

rost. rod I.

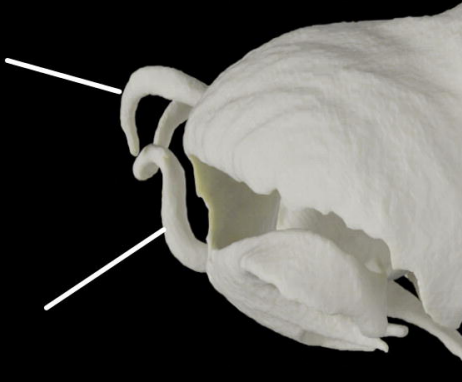

rost. rod I.

(d) pre. font.

$1 \mathrm{~mm}$

scr. cart.

rost. rod $\mathrm{m}$.

$2 \mathrm{~mm}$

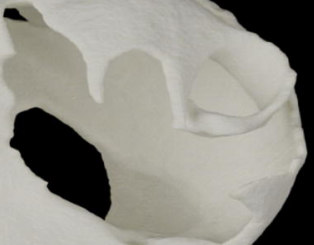

intn. pl.

(b) rost. rod I.

rost. rod $\mathrm{m}$.

supoph.

for. ant.

supoph. for.

pre. font.

suporb. ridge
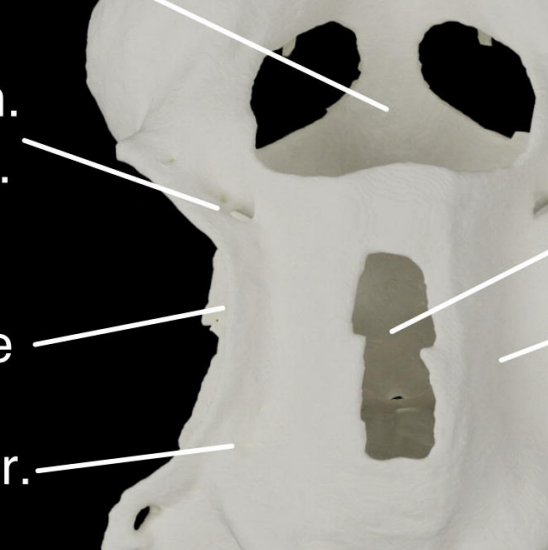

$2 \mathrm{~mm}$

hyomand. art.

postorb. proc.

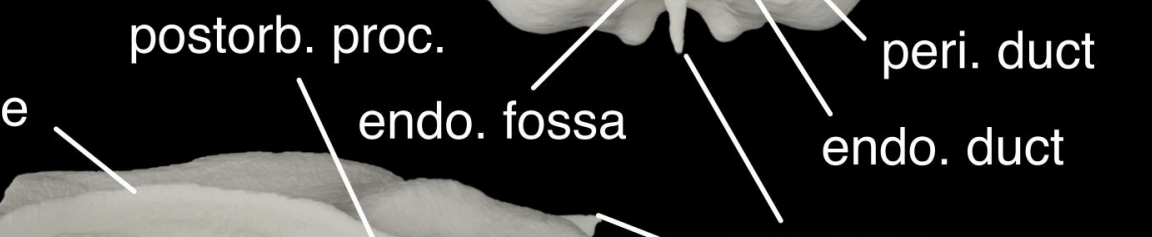

suborb. shelf

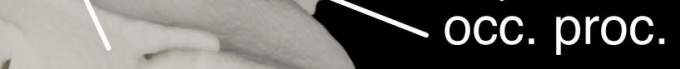

unchond. - lat. Lor. postorb. can. for.

$2 \mathrm{~mm}$

0

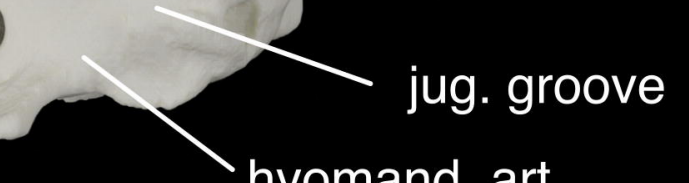

hyomand. art.

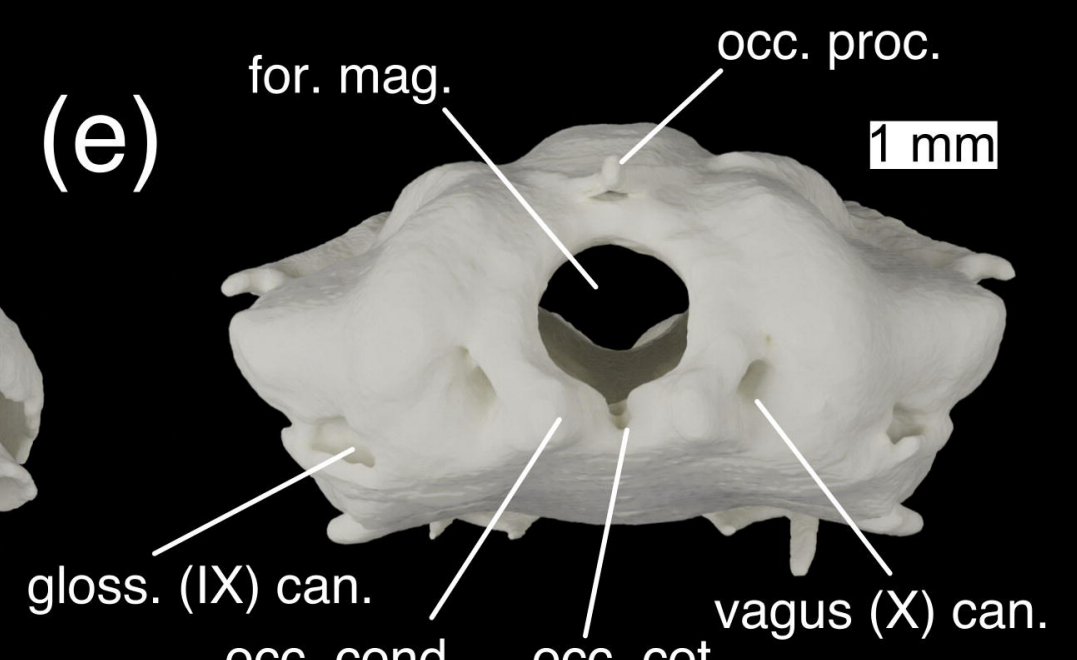
occ. cond. occ. cot. 
(a) neurocranium

hyo. ray vertebral

scapulocoracoid

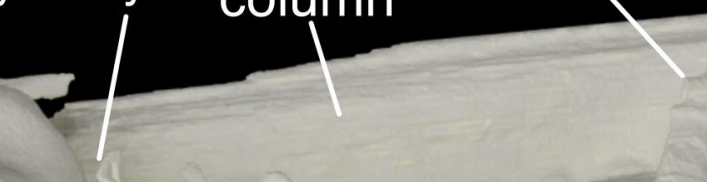

(b) palatoq. lab. d. lig. ethpal.

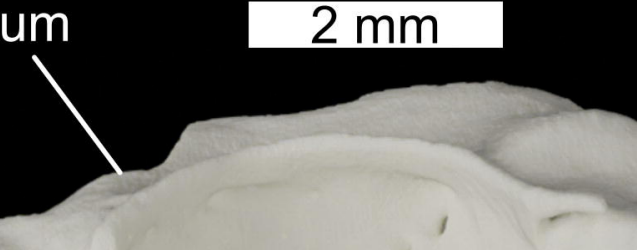

(c) $1 \mathrm{~mm}$

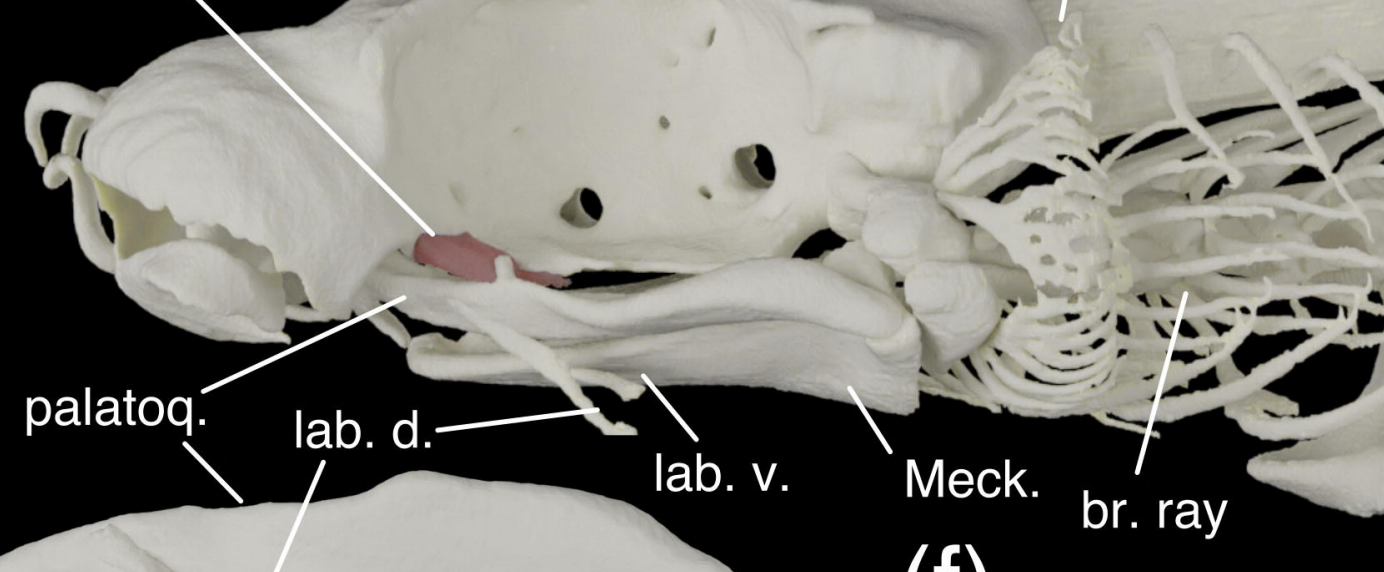

(f)

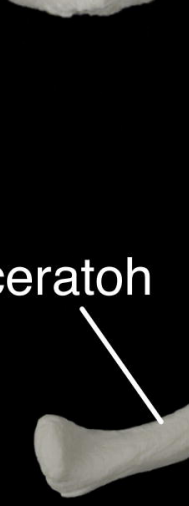
palatoq.

hyomand.

eth. proc.

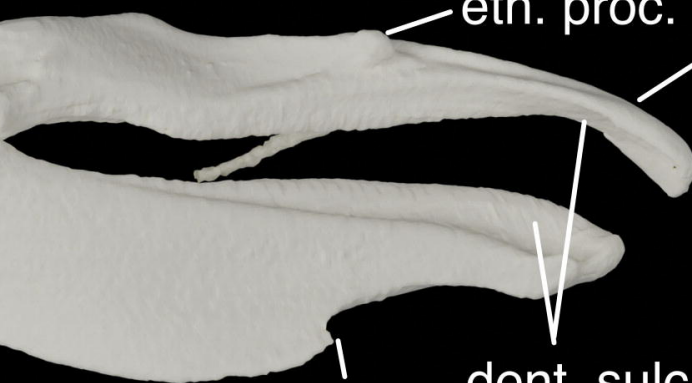

med. proc. Meck. dent. sulc.

(e) med. foss.

eth. proc.

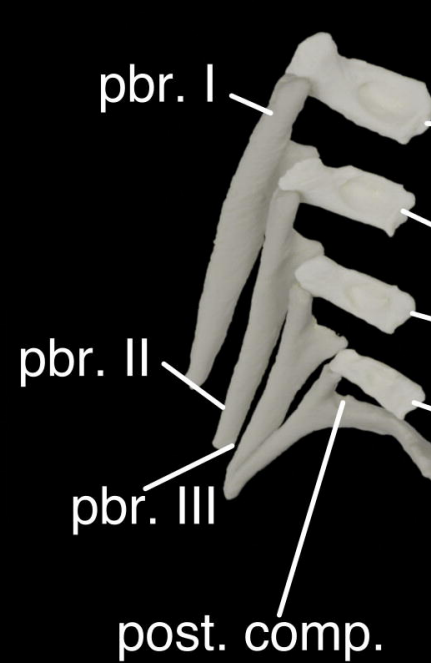

cbr I

cbr

cbr III ebr. IV

cbr IV

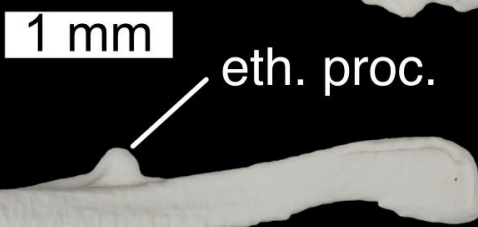

post. comp. 
abd. (IV) prof. for. supoph. (b) m. obl. sup. oph.

m. rect. m. rect. supoph. for. ant.

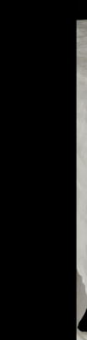
for. for. post.

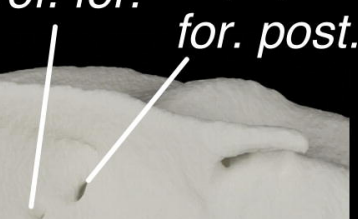
m. rect. med. orbnas. ant. opt. (II) eff. pit. v. oculom. can. cer. v. for. pseud. (III) for.

$1 \mathrm{~mm}$ trig (V) opt. (II) dors. lat. m. rect. vent. vent. 
$m m$.

arc. dors. m. subspin. mm. add. branch.

$2 \mathrm{~mm}$ acoma. (C) m. subspin.

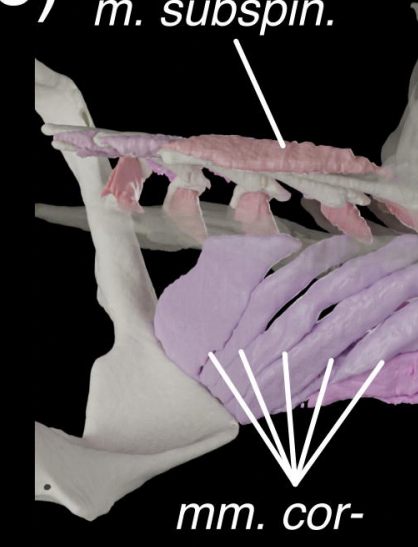

mm. coracobr. acobr.

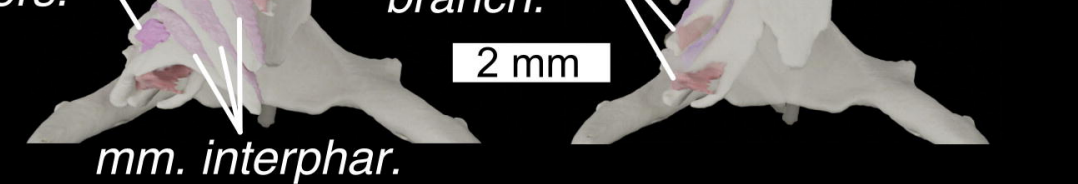
res

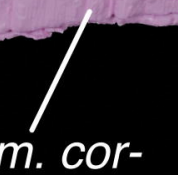

m. interacoma. 